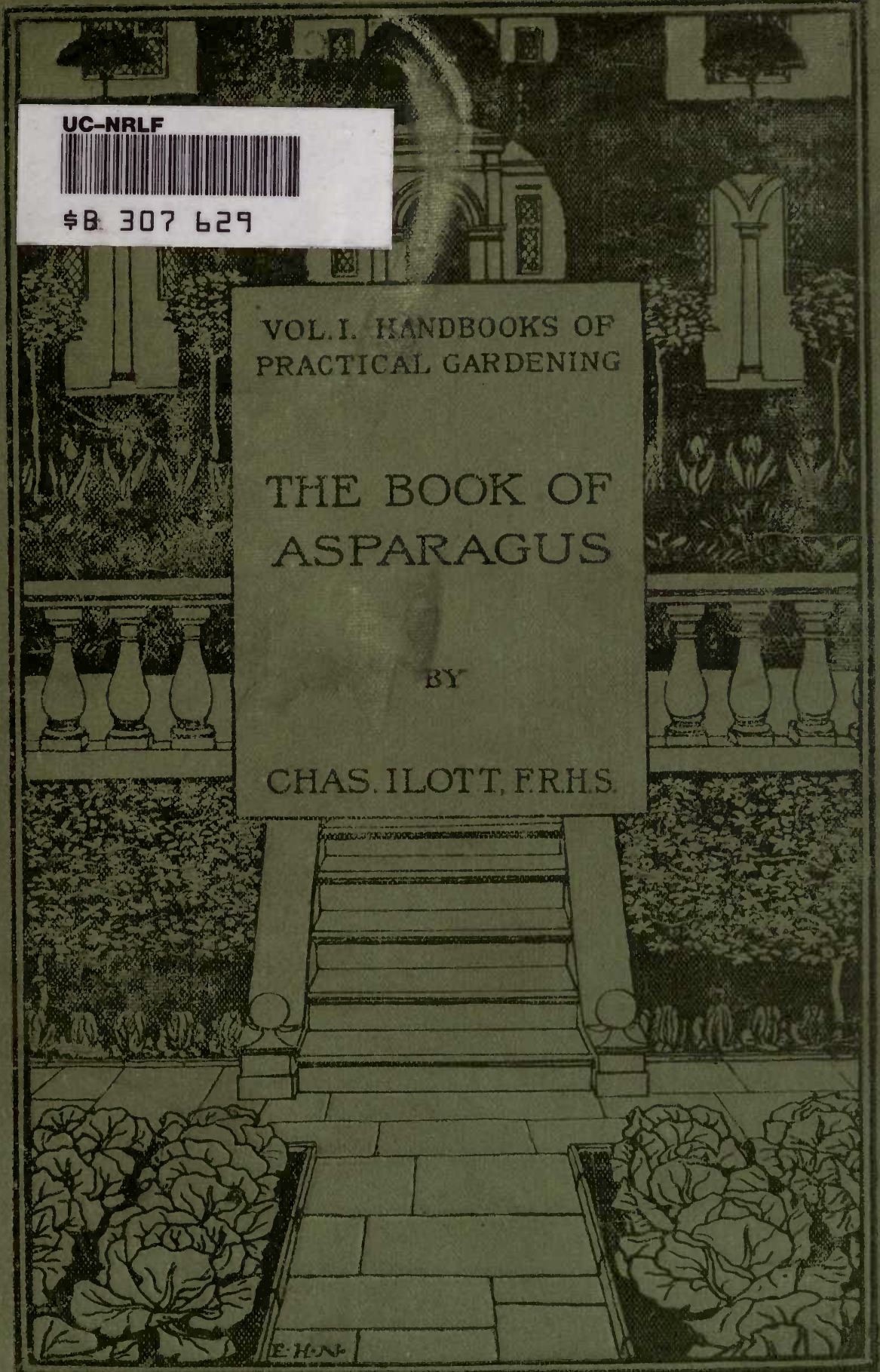




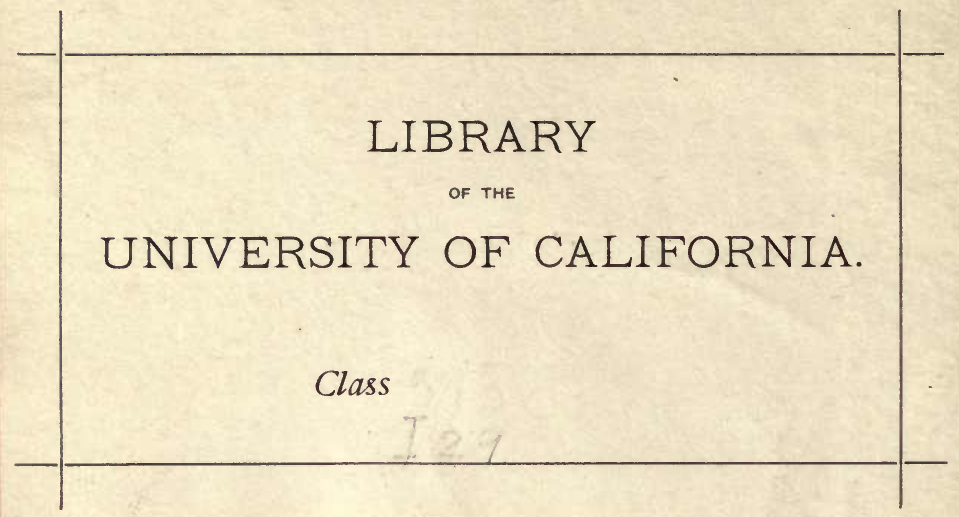


From the collection of the

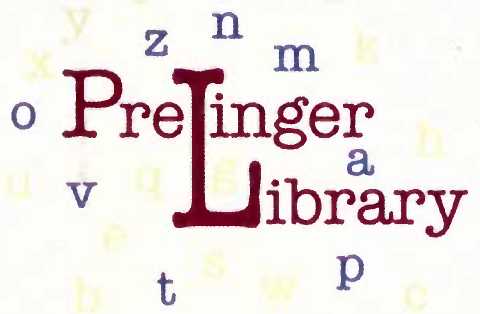

San Francisco, California 2006 

HANDBOOKS OF PRACTICAL GARDENING-I EDITED BY HARRY ROBERTS

THE BOOK OF ASPARAGUS 



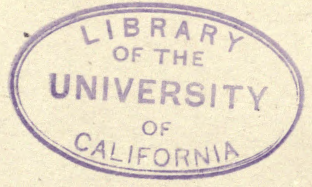




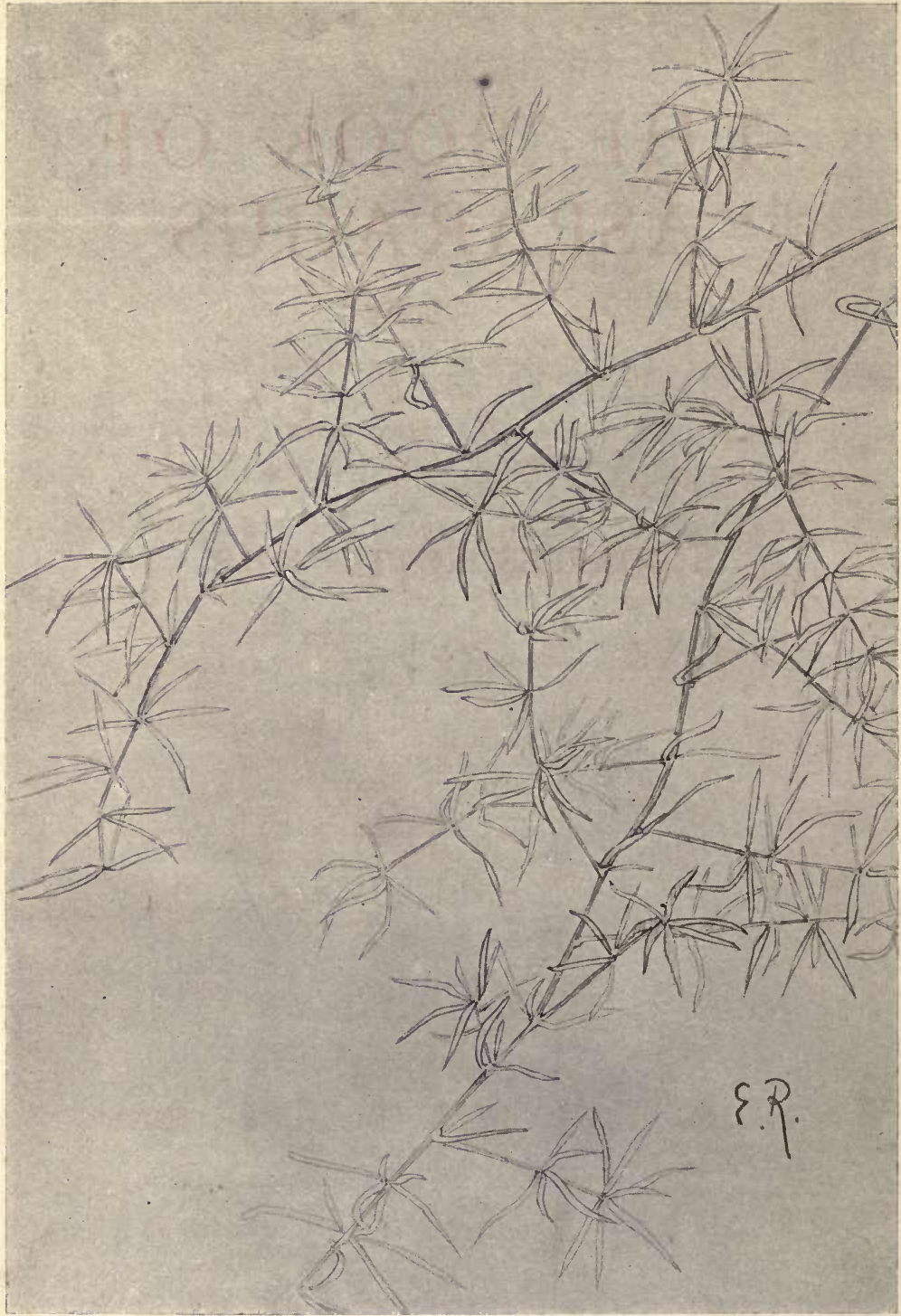

STUDY OF GROWTH OF ASPARAGUS SPRENGERI (ONE-THIRD NATURAL SIZE). 


\section{THE BOOK OF ASPARAGUS}

WITH SECTIONS ALSO ON CELERY SALSIFY SCOR'ZONERA ANI) SEAKALE

CHARLES ILOTT, F.R.H.S.

LECTURER ON HORTICULTURE TO THE CORNIALL COUNTY COUNCIL

TOGETHER WITH CHAPTERS ON THE HISTORY, DECORATIVE USES AND COOKERY OF THESE VEGETABLES BRARY BY THE EDITOR

UN VERSITY

OF

CILIFORNIA

JOHN LANE: THE BODLEY HEAD LONDON AND NEW YORK. MCMI 


$$
\begin{aligned}
& 53^{325} \\
& 16
\end{aligned}
$$

\section{GENERAL}

Printed by Turnbull \& Spears, Edinburgh. 


\section{CONTENTS}

EdroR's Note . . . . . . . . . . vii

The Culture of Asparagus $\quad$. $\quad$.

SOIL AND SITE $\quad$ - $\quad$ - $\quad$ - $\quad$.

VARIETIES . . . . . . . . 2

SEed-Beds .

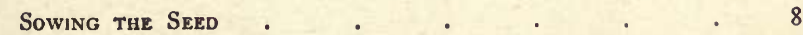

Positions for Prrmanent Plantations . . $\quad 14$

Solls for Permanent Plantations . . 15

Preparation of the Land for Permanent Plantations . 16

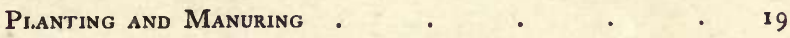

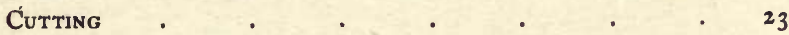

Sowing in Permanent Beds, with a Discussion on Over-

Forcing . . . . . . . . . . . 26

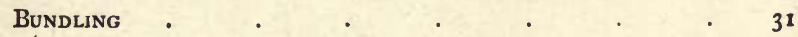

MARKets . . . . . . . 36

Insects ANd Diseases $\quad$ - . . . . . 37

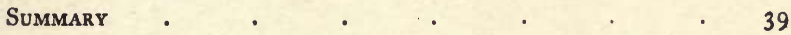

The Asparagus as a Decorative Plant . . . 40

The History and Cookery or Asparagus . . . 50

The Culture of Seakale . . . . . . . 64

General Description a . . . . . 64

Propagation and Culture . $\quad$. $\quad$. . . 67

Forcing .

MARKETING . $\quad$ - $\quad$. $\quad$. 77

vii 


\section{CONTENTS}

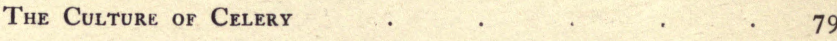

Sowing THe SeEd .

Planting and General Treatment . . . 83

Insect Pests

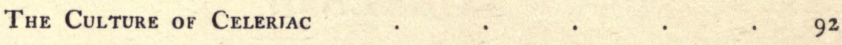

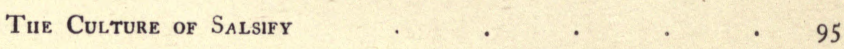

The Culture of Scorzonera . . . . . . . . . . 98

Historic and Culinary 


\section{ILLUSTRATIONS}

Study of Asparagus Sprengeri (from a drawing by Ethel

PAGE

Roskruge)

Frontispiece

Bundles of Asparagus as Prepared for Cooking . $\quad$. 3

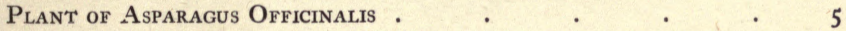

Roots of One-year-old Asparagus Plant a . . . 7

Roots of Two-year-old Asparagus Plant a . . $\quad 9$

Roots of Three-year-old Asparagus Plant . . 13

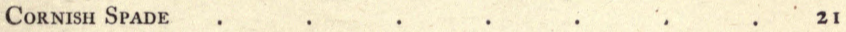

Asparagus Sprengeri $\quad$. 4 .

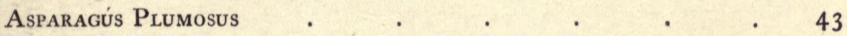

Asparagus Tenuisimus $. \quad . \quad . \quad . \quad . \quad . \quad 47$

Seakale . . . . . . . . . . 65

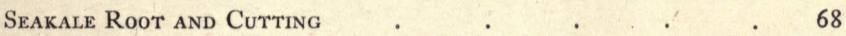

Celery . . . . . . . . . . 80

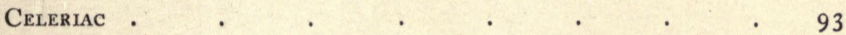

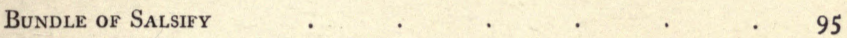

SALSIFY Roots . . . . . . . . . 96

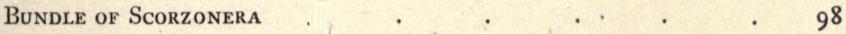





\section{EDITOR'S NOTE}

THis volume is the first of a series of handbooks which will deal from a purely practical stand-point with the culture of the various fruits, vegetables and flowers which are grown or might advantageously be grown in English gardens. An attempt will be made by the writers of the various books to sift the advice of tradition, and only to recommend such treatment as recent science has suggested or recent experience confirmed. These books will not attempt to compete with the many volumes-often very charming and beautiful volumeswhich have been written on the poetic aspect of gardens and gardening. Their aim, on the contrary, will be to provide the instruction necessary in order that useful and beautiful gardens may be created. To others will be left the work of expressing their appreciation of the products and pictures thus obtained.

The authors of the volumes to be issued in the series will be selected not so much for any literary ability which they may possess as for their practical knowledge and especially for their practical experience. $\mathrm{Mr}$ Charles Ilott, the writer of most of that part of the present book which deals with cultivation, has for forty years been engaged in the practical study and culture of the vegetables on which he now writes. As one of Messrs Sutton's experts, he had peculiar opportunity of gathering knowledge of certain branches of gardening, the value of which cannot be over-estimated. Recently he has been engaged by the County Council of Cornwall in experimenting on a large scale with a view to 
determining the most suitable crops for extended culture in that county and the most suitable methods of culture of those crops. His lectures throughout Cornwall have already, though he has been but a few years in the county, very considerably modified the gardening practice both of private and market growers.

As in the case of the cultural advice, so in that part of the book which deals with the preparation of the vegetables for the table, only such directions and recipes are given as have borne the ordeal of careful experiment.

The photographs used to illustrate the book have been chosen more with a view to explanation of the text than as beautiful pictures. In the case of the decorative species of asparagus selected as subjects for the camera, young specimens have been purposely chosen as they show better the peculiar character of the foliage than would the more densely packed branches of older and more beautiful plants. For the courteous loan of blocks showing the appearance of some of the vegetables as sent to the market we are indebted to Messrs Vilmorin-Andrieux of Paris, perhaps the greatest seedsmen of the world, and to Messrs Bunyard of Maidstone, the well-known and excellent growers of fruit, roses and vegetables. The editor also takes this opportunity of thanking those ever-courteous nurserymen, Messrs Kelway, of Langport, for gifts of seeds and roots, which will be of help in illustrating future volumes in the series. 


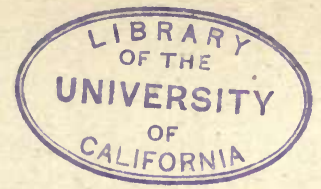

\section{THE CULTURE OF ASPARAGUS}

\section{Sorl AND SITE}

Asparagus grows wild in England, notably at Tintagel, near Camelford, and at the Lizard, near Kynance Cove, where it grows on the almost soilless rocks, the spray of the sea frequently washing it. This gives us hints as to culture, for it is found to take up its abode in warm positions where silicious soils abound, and, although close to the sea, it is not found growing in it, but in well drained soil on the sloping sides of rocks or cliffs. Yet there are probably few plants which respond as does this to high culture, although it thrives to a certain extent on silicious matter, or on rocks to which it seems but desperately to cling; and under the best culture the roots will grow down to a great depth, though only in a good rich, sandy soil. I understand that asparagus grows wild also in the Fen districts of Lincolnshire, and, indeed, one may say that almost anywhere, if only the plants be placed in soil of a light, sandy, friable nature, the growth is most rapid.

Many methods are adopted, and many opinions exist as to the proper method of growing the best class of asparagus, but I have found that all agree upon one point, which is that the nature of soil most suitable is a good rich, friable, sandy soil. Furthermore, all admit that a clay soil is the worst, and of this soil I had some years ago much experience. I grew asparagus on a strong loam resting on cold and heavy brick clay. I had no other soil, and, as asparagus had to be grown, in order somewhat to overcome the difficulty, I used all 
kinds of refuse to make the soil workable. I burnt some of the stiff soil, and I brought all kinds of leaf soils, burnt rubbish, manure, and even old mortar and plaster. Then I threw up the beds well above the general level and manured heavily on the surface in order to keep the roots "up." It was hard up-hill work, as is always the case when one is trying to grow plants in unsuitable soil. In spite of all my labour, I did not feel satisfied with the results. Yet we had fairly good crops, but I never depended on beds older than six years for asparagus of the finest quality. Nothing of this kind need be feared in dealing with suitable soils, for on such I have seen beds planted only two years and thought they were old established ones. When proper soil can be found-soil, that is, of a good sandy nature-it matters not at all in which county it be, if only such be naturally drained, little fear need be entertained as to results. Important it is that care be exercised in selecting our soil, but the site is also of the utmost importance, as a good sunny position somewhat but gently sloping to the south is quite necessary to success in asparagus culture. If protection be afforded by screens on the western side, or on the side of the site whence the prevailing winds sweep, so much the better. The importance of this will be seen later.

\section{VARIETIES}

There are many so-called varieties, yet they differ but little. Messrs Sutton and Sons of Reading have two-Perfection and Giant French-which are somewhat distinct. They are both excellent kinds, but whether they differ from others going by different names I do not know, for culture has a great deal to do with the appearance of asparagus as of human beings. A variety which is sometimes well grown, and sometimes the reverse, varies much in appearance, thus favouring the 


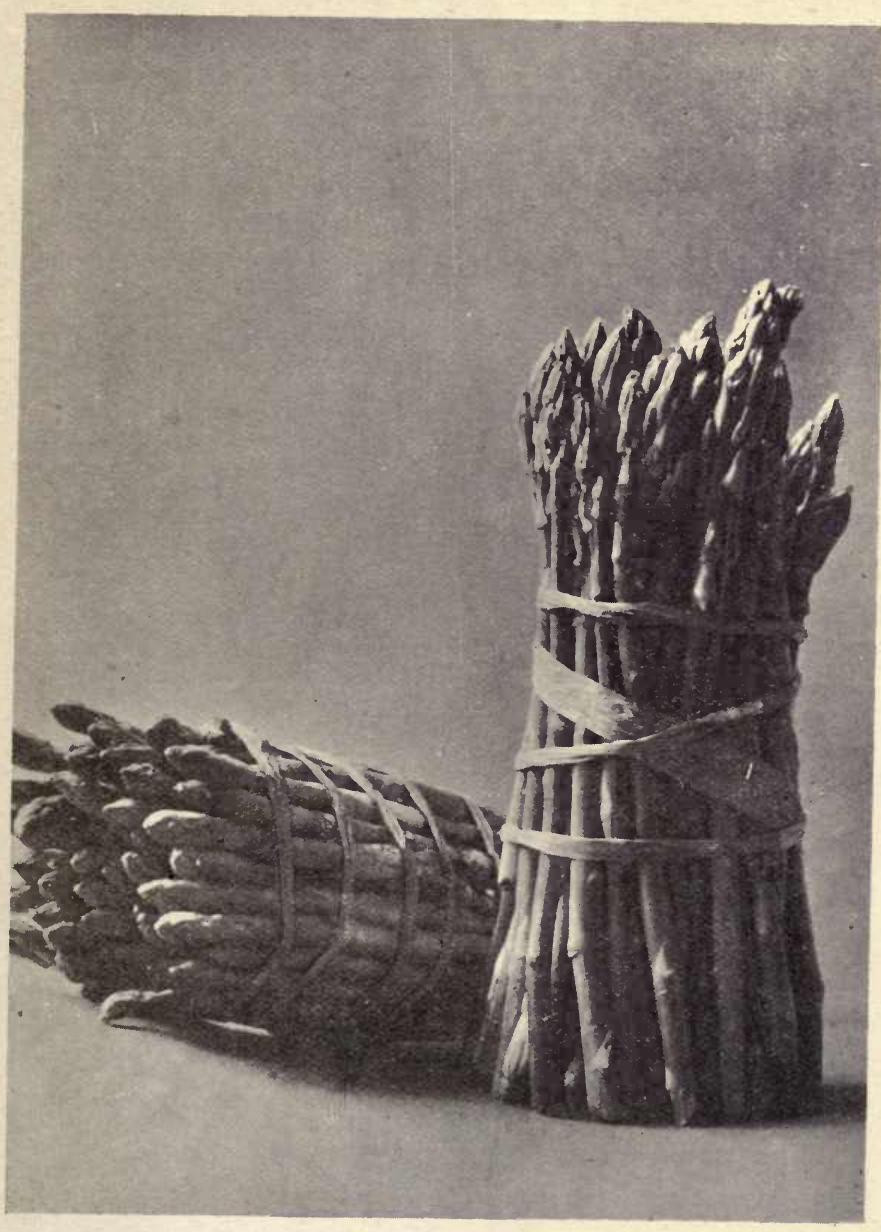

BUNDLES OF ASPARAGUS AS PREPARED FOR COOKING 
$=$ 
idea of a difference of variety. Two other possibly distinct varieties are Argentenil Early Giant and Argentenil Late Giant, which latter probably keeps longer in the cutting season by furnishing shoots later than the first named. Connovers Colossal is another good kind, but not superior to those named above.

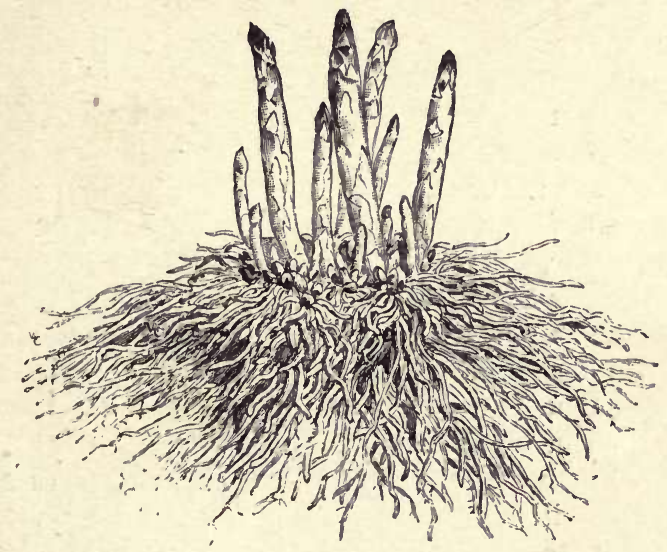

Palmetto reached me a few years ago with a startling character. It was said to be both earlier and larger than any other, but planted side by side with all the kinds above mentioned I have not yet found it display its alleged virtues. It came from America, and it is possible that it went over there first from Europe, probably from England, for I find it about as good as many others. As to size, it is smaller than Sutton's Giant French. The only other variety which I am going to mention is one which was sent out by Messrs Bunyard. They named it Harwood's Early, and it is noteworthy as being alleged to be the earliest to become fit for the markets. It certainly has in my experience for three years in succession started before the other kinds. 
There is, however, as I consider, far more importance in soils, sites and general cultivation than in difference of variety, and, whereas the cultivation differs materially, the varieties do not, in any great measure, differ from one another. I take it to be a boon to growers that this is so, for if asparagus were afflicted with as many varieties as are peas, potatoes and numerous other vegetables, we should every year be growing a few as good as, and many worse than, those which we now possess; for if the statement of Pliny be true that three sticks of wellgrown common asparagus weighed a pound even in his day, I do not think that we require any further waste of labour in endeavouring to produce larger varieties until we know how to grow those which we already have. What the Romans did they mostly did well, for theirs was an age of personal, individual energy. Ours, on the other hand, is one of superior scientific knowledge and enlightenment. We put our trust in what we know rather than in what we do. In this book, as far as I am able, I will give the results of my experience of thirtyfive years with asparagus-having grown it in various counties, in various soils, and on various sites.

\section{Seed-Beds, and how I make them}

A plant benefits no more than does a child in its infancy by being starved and neglected. If there is one plant more than others that in its early career should not be stunted, it is asparagus.

The best time of the year in which to sow the seed is the month of March, and the seed-ground must be clean and rich. The latter quality is more easily obtained than the former, but there should be no careless- ness as regards the condition of the land. A good open piece should be selected-light and friable, even lighter for the seeds than for permanent plantations. 


\section{SEED-BEDS}

The seed does not readily germinate, so that if the soil be foul a good crop of weeds will be the result, and with these it will not be easy to deal.

Therefore, in order to secure clean land, prepare the

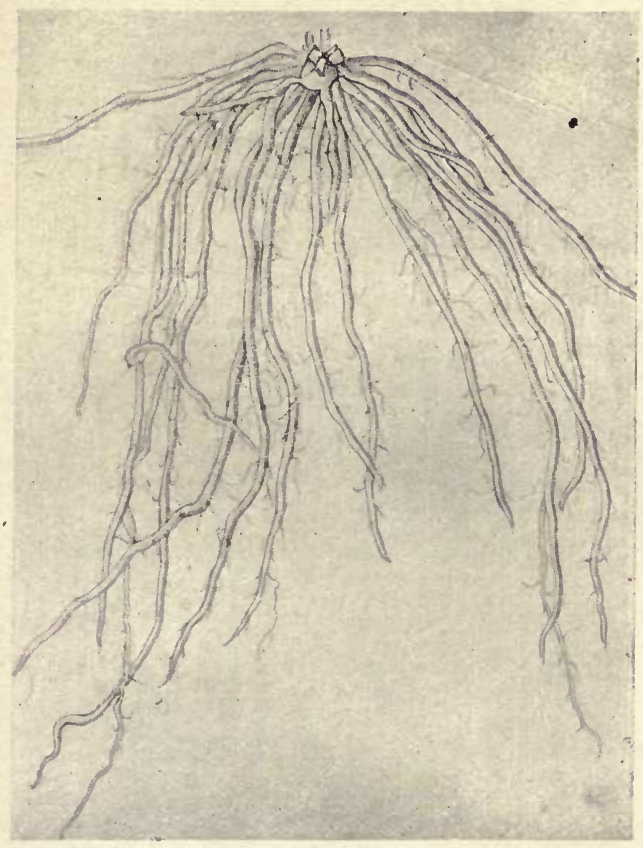

ROO'TS OF ONE-YEAR-OLD ASPARAGUS PLANT-ONE QUARTER NATURAL SIZE

beds early, by well manuring them and by having them dug early in the winter, throwing up the soil roughly. This will be the means of having it well pulverised by frost. On a dry day about the end of February the ground can be lightly forked over, but not so deeply 
as to disturb the manure which was previously dug in. After so doing, leave it for the weeds to germinate, and when they appear harrow the ground, or with a largetoothed rake disturb the soil a few inches deep, and again leave it. In like manner, if possible, allow the next crop of weeds to start, and proceed again as before. Otherwise, long before the young plants appear, the beds will be covered with weeds, as indeed is the case with most seed-beds. It is really impossible to be too careful at this stage, as precautions taken now will save much trouble later on.

Work the land down so that no clods are buried underneath; though the kind of soil specially adapted for asparagus culture will scarcely allow of such. Lumpy soil, if treated as suggested, will crumble at the least touch, and this is what seeds of all kinds like. In March all seeds, if a good day can be secured, should be sown in the afternoon. In the morning a rake should be roughly passed over all ground intended for sowing, and the soil will then on a sunny day be in beautiful order in the afternoon for drawing drills. If no earth adhere to the boots, it is an indication that the soil is in good condition.

\section{Sowing The SeEd}

Whatever seed you may require, get your supply from a good source. Avoid cheap seeds of all things. I would not wilfully sow a doubtful seed whether received from a friend or from a member of the trade. I know a little about the seed trade and also something of friends. Don't waste a season rather than spend an extra shilling on good reliable seeds. I have never really grasped the meaning of the word cheap; it is a word which seems to mean that you are getting your 


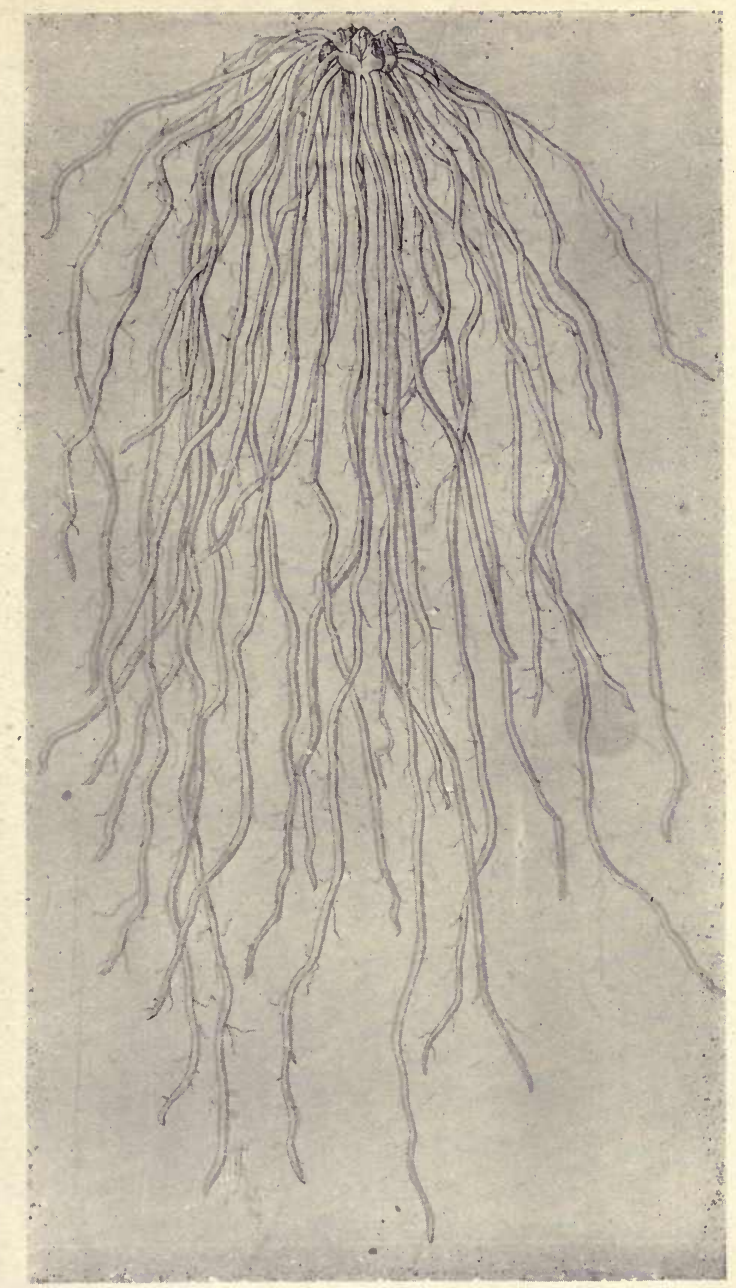

ROOTS OF TIVO-YEAR-OID ASPARAGUS PI.ANT-ONE QUARTER NATURAL SIZE 
MiBRARY
UNIVERSITY
UNIVE 
money's worth and a trifle over, and it of ten means also that you will get what no one else wants.

Having purchased reliable seeds, draw drills about two inches deep and a foot apart. Anyone accustomed to sowing onions can do this, but as the seeds are four times the size of onion seeds a wider drill might be used. Sow thinly, and lend no ear to the people who say that you can thin asparagus after it is up. Three pounds of seed will sow rows a mile in length. I sowed this amount of seed on Easter Monday, three years ago, and as a result I raised twenty-five thousand plants, which are now strong and fit to produce splendid asparagus. A friend of mine, at the same time, used the same amount of seed in a length of three hundred yards. His plants came up thickly, and well they looked, but they never reached a foot in height during the first year, whilst mine topped twenty-six inches. My thick-sowing friend would find a great difficulty in parting his plants; the crowns would be weakly, and the roots would be so broken in parting that good growth would be long postponed. When the seed is sown I mix together two parts bone meal, two parts kainit, and one part sulphate of ammonia, and sow the mixture in the drills at the rate of about one pound to ten yards' length of drill, carefully covering it up with a rake. I referred to the drills as being much like those made for the sowing of onions, but there is this difference, that when sowing asparagus the ground must not be trodden unduly before or after the sowing. Onions are required to bulb well, hence it is necessary to "firm" the ground for them, but it is desirable that asparagus roots run freely near the surface, and a loose soil is by far the best to encourage this habit. The plants will not appear quickly whereas the weeds will, so that if a mark can be made to show the seed row so much the better; but generally the row can be dis- 
tinguished by the buried manure keeping the ground a little moist, so that a dark line is observable, and a Dutch hoe can be used between the drills before any plants can be seen. When they shoot through the ground the young seedlings are very small, so that any one unaccustomed to their first appearance would not see them. All weeds must from the first be kept away. This is a very important matter, as young plants are smothered in weeds by a few days' neglect, for of course on well-manured lands weeds will grow rapidly and vigorously. Indeed, I like to see land on which the weeds grow freely, for it speaks well of the richness. Weeding and hoeing are the two principal items throughout the first season, but if the plants are not growing fast a slight sprinkling of nitrate of soda will greatly stimulate them.

\section{Positions for Permanent Plantations}

I have said a word or two in reference to the proper sites for asparagus culture. Many suitable places could easily be found in almost every county of England where with such soil as already described no fears need arise as to the ultimate success.

Every one will admit that in growing asparagus, earliness is desirable. Hence it is necessary to obtain the warmest spots on which to grow it, preferably a spot with a full southern aspect. I alluded to the desirability of affording protection from the roughest winds for, when the plants are growing up during August and September, we are occasionally visited by rough gales and the stems are in many cases blown down, and sometimes broken off. Where such happens, new and premature growths will follow, which of course weaken the plants and lessen their next year's yield. The French growers put sticks to their plants to prevent 


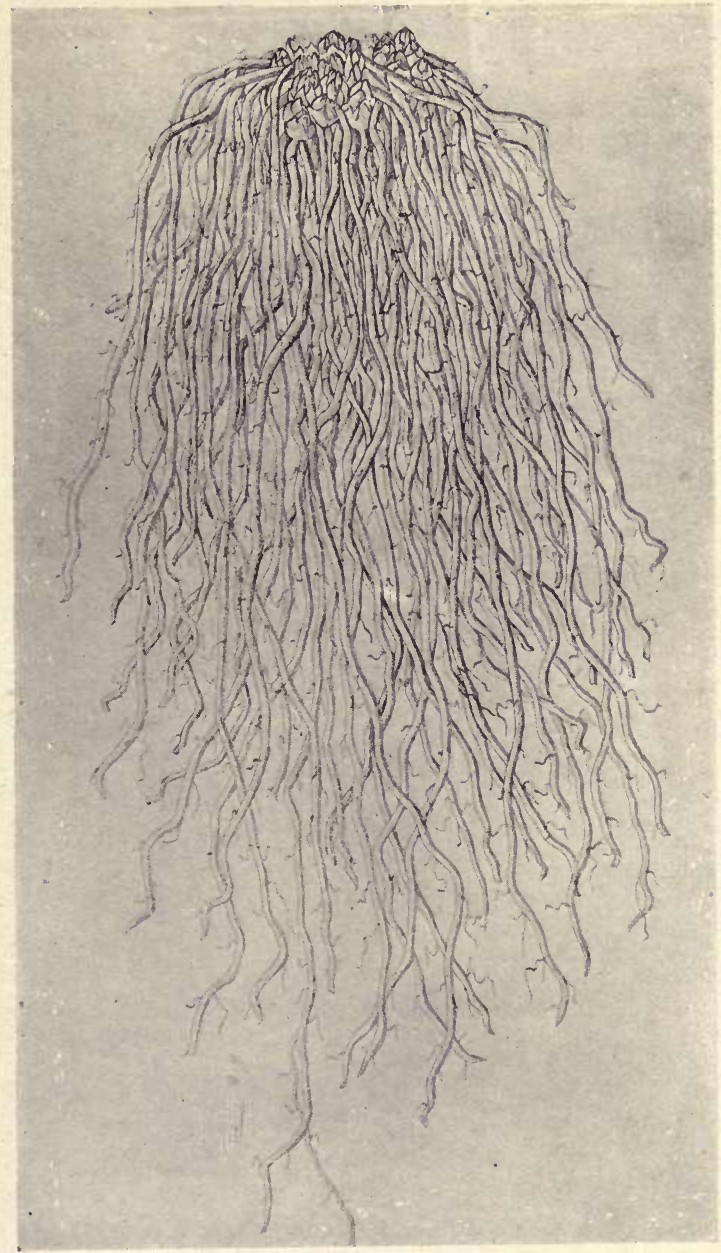

ROOTS OF THREE-YEAR-OLD ASPARAGUS PLANT-ONE QUARTER NATURAL SIZE 


\section{OF THE Y
UNIVERSITY}

OF
ALIFORNIA 
this, but it is rarely that one finds such care in English gardens. The southern site, of course, is always the warmest, and when well drained in addition nothing more can be desired. I know that such positions are not always available, but when arranging for extensive culture, such places must be sought for. I know in the county of Cornwall alone many hundreds of acres with this ideal position, and yet such are utilised for ordinary farm crops (which, their owners allege, "do not pay").

\section{Soils for Permanent Plantations}

I scarcely need again revert to the kind of soil suited for the permanent plantation, but as there are several methods of laying out the beds and plantations, care must be exercised, for an ideal soil is not always at command. Where a porous subsoil exists on sloping ground as described with a good loam on its surface, nothing better need be desired, for such top soil is sure to be of a sandy nature and friable, and should this be naturally fertile as is usually the case, future success is secure. I spoke of asparagus being grown on clay soil in Berkshire and of how the roots were drawn to the surface by manuring. On such soils this is quite necessary; but, given a deep silicious soil, the deeper the roots can penetrate the better will be the crop of asparagus.

I remember some years ago the late $\mathrm{Mr}$ Shirley Hibberd writing in the Gardener's Magazine on the depth to which the roots of asparagus would travel if allowed. Some buildings were being erected near his house, and on a large heap of top soil which was thrown up $\mathrm{Mr}$ Hibberd was allowed to grow some asparagus. He mixed dung with the soil, and the plants grew so amazingly that some who saw them could not be convinced that they were not specimens of some new and superior kind of asparagus, and a gentleman actually 
wanted to purchase the plants at a fancy price. About four years from the time that the asparagus was planted, the plants were removed. It was then found that their roots had travelled to the bottom of the heap, some five or six feet in depth. Of course this depth of soil is quite unnecessary even if the best results be aimed at, yet it is well to know of what the plants are capable. The difference in the home of the original plant on the rocks and the deep earth of the cultivated one, as just described, shows a wonderful adaptability, and also teaches us what can be done by altering conditions, or in other words, of what plants are capable when allowed unlimited privileges.

\section{Preparation of the Land for Permanent Plantations}

Here again is a matter of the first importance, for having decided to grow asparagus, whether on the large scale or the small, the same preparation is necessary. Having fixed on the site, as much manure as possible from stables, pig-sties, or cattle yard should be taken in the autumn, and either ploughed, or, better still, dug into the ground. This digging should be done as deeply as the soil will admit, but in no case should the subsoil be brought to the surface, no matter of what nature it is. Let the land remain in a rough state, as the plough or spade leaves it. As this work is to be of a permanent character, be not stingy with the manure, for no more will ever again be placed under the surface as long as the plantation remains. In the spring or late in winter, preferably about the end of February, the land should be crossed with a scarifier or a heavy harrow, and then left till near the time of planting, which is the middle or end of March. It will be advisable about two days before the planting takes place again to harrow the 
ground, so as to get it fine enough for working out the drills.

Beds or Plots.-These are the two principal systems of growing, and the choice between them should depend on circumstances, not on what others do; for blind copying of neighbours is the cause of much of the failure in every branch of gardening. We must study our position and work accordingly. Why do so many people grow asparagus in beds? I mean the old orthodox beds, of three or four rows in a bed, the rows eighteen inches apart, and the plants a foot apart in the rows. In many gardens the plants are even closer together than this. I confess that I have planted a good many such beds. I confess also that I did this often because so many other people did likewise. I do not wish to sneer at my predecessors, for probably they had reason for the course they adopted, whereas I had none. However, sometimes one does wake up and become bold enough to think for oneself. Such an awakening came to me in the matter of asparagus culture, and, as I am going to advocate in the following pages one particular style of planting, I will first explain my prejudice against the system of planting in beds. Some folks will say that beds can be easily tended, others will say that it is easy to gather the shoots. There is this other alleged advantage with the bed system, namely, that you can clean out your alleys after manuring the beds, and evenly spread the soil over the surface.

Now all these contentions I consider fallacious, thus, no doubt, calling down thunderbolts on my head. The greater ease of rendering attention, the facility for gathering the crops, the practicability of annually cutting out the alley and throwing the soil thus spread over the beds, all these things I consider worthy of small notice.

Before we discuss the subject further, the reader should 
look at the illustrations showing one-year, two-year, and three-year-old plants. It at once appears to one's reason that the roots shown therein require a very long run, and as the principal feeding roots, or the portions which take up the most nourishment from the soil, are those at the very end, these roots are seen to travel a great distance. On the day on which I write, I, with one of my assistants, took up the three-year-old plant shown in the drawing, and found roots two and a half feet from the crown of the plant entangled with its neighbour's roots, and I even had to break them off because of the entanglement. Why not treat these plants individually in the same way as broccoli, Brussels sprouts, or even gooseberry trees are treated? Asparagus roots, if properly cared for, will run farther than any of these, and we all know what would happen were we to plant either of the plants named a foot or eighteen inches from crown to crown.

The French give their plants a space of three to four feet a-piece, and wisely so, for we all know that large asparagus commands the highest prices in the markets. If the soil where the plants are to be placed be wet, it must be drained. If it be so low that it cannot be drained, it is no earthly use to expect good results, but if the ground be wet though not water-logged, have each plant raised on a little hillock, and we shall have all the advantage of the bed system. Of course it might be urged that there would on this method be no alley. That is one of its advantages, for when one bears in mind that in order to keep an alley defined the plants on either side, viz., the outside plants, must have their roots annually shaved off with the spade-of all methods the most barbarous. I have practised this savage rite myself when, as a pupil, it was my function to execute the orders of others rather than to think out practice for myself. 
The best asparagus cannot be secured unless ample room be allowed for development, and there should never be any difficulty in the matter of space in walking freely between the plants at any time, without the introduction of alleys.

So now for the planting.

\section{Planting and Manuring}

For planting, none do so well as one-year-old plants; and when people ask me at what age I would recommend plants to be, I know that they have all to learn. The principal reason why one-year-old plants are best, is that the roots do not get broken so much at this age as when older, and if carefully taken up (and in this matter one cannot be too particular) few rootlets need be left in the soil. Well-cultivated two-year-old plants grown in rich soil would be really very difficult to get up without injury. When I hear of three-year-old plants being bought, I know that (with the exception of those prepared for forcing) they have been badly cared for-for a well-grown plant of that age taken up by me to-day, shown in the drawing, weighed, after the earth had been washed away, two pounds, and some of the roots were left broken off in the ground. I would rather plant the one-year plant than this older one, large as it is, however carefully taken up.

Taking up the Plants. - It requires two people to take up the plants-a man and boy. If the latter be a good one he will do better than a man, for his work is carefully to take each plant as the man digs it up with a fork-not a spade, to separate the plants if necessary, and carefully to put them in a wheelbarrow, or, if they have to be taken far, in large flat hampers called "flats." These can be put in carts, and so taken to the plantations. No more should be taken up than can be planted 
immediately, for generally at the planting season (the iniddle or end of March) the sun and winds are very drying, and this is very injurious to the plants, hardy as they are. If any plants are still out of the ground when night stops the work, they should be covered up with mats or bags, and if such mats, etc., be made wet so much the better. These little details, though small, are by no means superfluous.

Two or more men should now be getting olit the drills. I use the phrase "getting out," because they should not be "drawn," as is generally done. The long-handled Cornish spade is best for this work (see Fig. 4). This tool will be new to many; but it is admirably adapted for the purpose, for, by walking backwards, a man will easily shovel out the soil to a depth of three inches, and the drill will be a foot wide. This will allow room for the roots to be well spread out, as should be very carefully done. There must in fact be no careless work at this stage, as ultimate success or otherwise depends on these preliminaries. All available hands must be employed for this work of planting, because there should be no lingering. The quicker the plants are under the soil the better; but before we begin, we must settle the distance to be allowed between the plants. As I have said, the more room the plants have the larger the asparagus will be. The French know this, and give much more room than we do. I have found a very good distance between the rows is three feet, one foot to eighteen inches being allowed from plant to plant. I have also planted in rows three and a half feet apart, and the results have reflected the greater space, so that what the grower will be guided by is the size of the asparagus he wishes to grow and the markets he is about to supply. If he allow either of the above distances, he will, with good treatment, produce asparagus of good quality. A line must be stretched across the 
ground to get the drill straight. This will require, of course, two men, who, with a spade apiece, will take out the soil to a uniform depth. The best size is twelve inches long and twelve inches at the base, graduating as shown in the figure. The advantage of this long-handled spade is that the sides of the drills are as deep as the middle, which result a hoe will not easily accomplish; but a greater advantage is, that after the first drill is taken out and the second one commenced, the soil from this second will exactly cover up the first, and the third will cover up the second, and so on till all is finished. I had never seen this tool till I came to Cornwall. It is the Cornishman's one tool-he uses it as a spade, a hoe, and a fork (for he takes up his potatoes with it). With it he sets his broccoli and cabbages, and many other things besides; in fact he scarcely wants a tool but this to do every kind of work, and a tool-house in a Cornish market-garden contains very little else.

Following the men with the drills, a man and a boy should put the plants in the rows. Whether the plants in the rows are to be one foot,

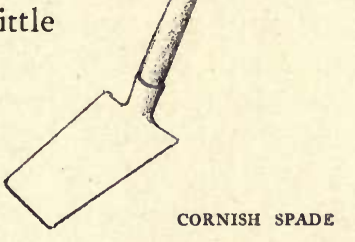
one foot and a half, or two feet apart, they should be put at their correct distances, whichever be selected. The boy, carrying a basket full of plants, should drop a plant at the right place, and the man should evenly spread the roots out. Could a reliable boy be found to do this, he would be better than a man, for the boy can stoop more easily, and so could handle the roots better. Either before or after the roots 
are placed in position, a good sprinkling of manure should be put in the drills. Some growers advocate about six hundredweight of guano to the acre ; others would mix equal parts of bone-meal, kainit, and superphosphate, quite two months before required, occasionally mixing and well turning, using about ten hundredweight to the acre. I know some people who are able to give such minutely definite instruction as to the application of manures that novices think their advice unquestionable, but after many years' experience of cultural experiments I must confess that I have not yet arrived at this infallible stage. Soils, previous cultures, and other causes upset calculations, and I am inclined to think that unless a chemical analysis of the soils be made no very definite instruction as to quantities of nitrogen, phosphates, potash, or lime can be given.

The planting having been finished, the drills finished off with a rake, the principal work throughout the summer will consist in strenuously keeping all weeds under, for these will grow freely, and, as the land has been well manured with dung and a good supply of artificials, stronger weeds will be in evidence than where the land is poor. Neglect will cause the plants to be heavily handicapped at this stage, for the roots are but just starting afresh after removal, and will not be benefitted by running a race with vigorous weeds for food. When the time comes to cut the plants down in the autumn no weeds should be found, yet I have seen nettles and almost every other kind of weed at this time of year developed into abnormal specimens, robust, and of gigantic growth. Nothing can show less common sense than having gone through all the work, and to all the expense of preparing the ground and planting the roots, to finish the season with a large crop of weeds. It is customary in the autumn to apply a large quantity of the best dung available, to dig it in and to throw earth over the whole, thus 
making the plants unnaturally deep. I would advise that this work be done late in January, a mulch being applied and just a little earth thrown over the manure to rot it. Where it can be obtained, stable manure or sea weed, well mixed with sand, is good for the plants, and if fish manure and night soil can be had so much the better. Every alternate year this mixture might be applied, and in the following year in November eight hundredweight of kainit. Early in March add six hundred weight of superphosphate, in May one and a half hundredweight of nitrate of soda, and in July one and a half hundredweight of nitrate of soda. Guano for a change instead of either of these annual dressings can be substituted at the rate of twelve hundredweight per acre, for asparagus seems to like any manures, and salt also can be put on with advantage at the rate of twelve to fifteen hundredweight per acre, but this is not so necessary when kainit is used, as this contains a large quantity of salt. This system of alternation will be better for the plants than the old way of putting on a heavy dressing of dung in the winter or autumn without any change from year to year.

\section{Cutting}

About the middle of February, a few inches of the surrounding soil should be thrown up over the crowns or plants, and for this purpose a top dressing of sand is helpful to add with the soil for earthing, as, when the gathering commences, the little hill over each crown can be drawn down, and instead of an asparagus knife being used the shoots can be broken off by the fingers. If a knife be used, I prefer an old pruning knife to the well-known asparagus knife. 'Take the top of the shoot carefully between your thumb and fore-finger, then with the knife in the other hand push it perpendicularly into the soil alongside the shoot which you are about to cut, then 
with a slight twist of the wrist sever the shoot as low as possible, and in so doing do not allow the knife to go too far, or young shoots near will be destroyed. A good many shoots just starting are often killed in this way.

There is much difference of opinion as to the length of "green" a shoot should possess, but none should be reckoned as first-class if the heads are loose. They should all be compact, and with a mauve or purple tint. Some varieties are a little darker than others, but, when well grown and robust, with heads compact and of the tint described, asparagus commands the best price. Eight inches is a good length. The first year that the plants produce a crop do not cut severely, but allow a few of the smaller shoots to grow up, and do not continue the cuttings so late as can be safely done with older plants. In the first year do not cut after the end of May-with older plantations I give orders on no account to cut after the fifteenth of June. Some people are never willing to forego cutting as long as good stems appear, but such are deservedly foredoomed to have inferior crops in after years. No other plant will tolerate the continual cutting which asparagus bears. Even horse-radish would object, and I know that thistles and docks cannot survive such persistent decapitation. Yet asparagus bears three months of continuous guillotining without apparent injury, and, though every shoot be cut off from the early spring till the middle of June, will recoup itself for the next year's onslaught.

Sowing in Permanent Beds, with a Discussion on Over-Crowding

There is yet another plan for starting asparagus culture which nearly every writer mentions, though few advocate. This is the process of sowing the seed where the plants are to remain. Good results might 
follow this practice, but for one reason or another they scarcely ever do. For one thing, most people try to snatch a crop of some kind while the asparagus is growing, thus treating the latter more as a secondary crop. As a result, the plants are stunted and the crop generally hindered. A writer in a recent issue of a prominent agricultural journal said that "the objection to using plants is that they suffer in being transplanted." I never yet found plants to suffer by the process if ordinary care be observed.

To the French, who plant their asparagus at such a great distance apart, the seed bed as a permanency would be out of the question, and is not entertained by them. Personally, I ignore this seed bed plan altogether. The writer whom I have just quoted also says that the plants used should be one year old. With this I quite agree. Later on he says, "The most convenient size for beds is three rows wide, with the rows nine inches apart and one foot from plant to plant and any length that may be desired. The beds may be planted either by seeding or by planting one-year-old plants in the manner before directed, but three rows together instead of one" (this refers to field culture for which in a previous chapter he gives a distance of three and a half feet from row to row, and nine inches from plant to plant). When I read this, I wondered where would be my one-year-old plants if only allowed a distance of nine inches from row to row and a foot from plant to plant. They would touch each other at the commencement if the roots were properly spread out. Of course no worthy results could be obtained under such conditions. I know that a good many people simply plant with no definite views. Such a case came under my notice not more than a year ago. A gardener had planted a good many hundreds of plants in a fairly good position, but the work had evidently 
been hurriedly done, for I found fringes of roots in straight lines which had never been covered up, for instead of being convex or flat the drill was concave. I remarked that he had been planting asparagus. "Yes," said the gardener, "we have got it in ; but how did you know since the plants are not up?" I explained that he had not covered up the roots because the drills were not wide enough. "Oh," he said, "they will grow all right, but I know you are so particular." "Yes," I said, " they will not die, for it is a pity that asparagus will stand much careless treatment." Otherwise, perhaps asparagus culture would turn out more satisfactorily, for though the plant is accommodating, it is only careful gardening which yields really good results. This impresses itself on me when I see nearly every way but the best generally dealt out to it. I think it would pay all intending growers to visit France and see French methods and results. There are certainly some good English growers, but there are ten indifferent ones to one quite first-rate. This is not a pleasant truth to write or to read.

\section{ForCING}

I am sure that all will admit the time allotted for cutting asparagus out of doors to be much too short to satisfy lovers of this vegetable. Therefore the art of prolonging the season-doubling the season I might say - must be a great item in its culture. I will here give several methods by which this can be done. Early asparagus is considered a great luxury, and very early produce fetches a high price, but there are many means of producing it in large quantities, which means I will here describe.

Forcing is a branch of culture which is much neglected. It is well known that asparagus cutting in the open 
should be allowed to proceed for about ten weeks only. From Christmas to March is a time of great scarcity of choice vegetables, and hence forced asparagus always command a ready sale and good prices, but even so the supply generally runs short of the demand. Yet there certainly should be no lack of supply, because asparagus is the easiest and most reliable plant to force of any I know. There is one most important matter to remember if this is to be done really well, which is that the plants must be well prepared for the work. I have forced all kinds, or rather plants of all ages, from twenty years old to two, but if the best results are obtained such plants as that shown in the illustration of a three-yearold plant should be used for the purpose. This plant was sown three years ago, taken up and planted in a row twelve inches from row to row and eight inches apart in the rows. Of course not a stem has been cut, except the ripened shoots in the autumn. Indeed, this is the secret of producing the best quality. Old beds can be forced, but the produce is unequal - a few good shoots, a great many small. I have seen well prepared young plants produce by the end of November by gentle forcing, asparagus as large as is sometimes found on old beds at their best in April ; but to prepare plants I would advise very liberal treatment. Plants certainly can be, and are well grown in less space than I have mentioned, but the greater the space the better the results. Well do I remember making a gentlehot-bed principally of oak leaves, and then bending rods over the beds, covering up with mats and old hop bags cut open. Such plants as I have described were taken up early in February, and placed on about four inches of light soil, and simply packed closely together, so that the crowns were only a few inches apart. They were then covered with soil three inches deep, the mats and bags being tightly fastened down over all. A gentle heat of 
about 65 deg. was thus maintained for several weeks. About three weeks from the time that the plants were put in, a host of buds were visible, and then the bags and mats on the sunny side were thrown back to the north side for several hours a day, when not too cold. I never saw such a uniform lot of shoots, scarcely a small one being among the lot; in fact, I never had or saw forced asparagus equal to them. Certainly the spring was mild, and the work was comparatively easy in consequence; but the means of success employed were well prepared three year old plants, and the steady heat which fermenting leaves always afford if properly stacked when collected. Had I plenty of oak leaves, asparagus forcing would be a very simple matter, for, although I have used hot water pipes for forcing, I never had such good results as by using leaves. I had equal success with seakale, both of these plants, in my opinion, being of better quality, especially as to flavour, when forced in this way than when other means are used. I have also, when a large heap of leaves has been collected, made the top of the heap flat, and taken two light frames and put over the surface. Then, with a few inches of light soil, plants such as before. mentioned were thickly placed, the lights put on, and a trial stick thrust in the centre about a foot or a little more into the leaves. Every morning the stick was pulled out and the heat tested, as can be easily done if when pulled out with one hand the other grasps the stick. By the touch the heat is approximately judged. A very gentle heat is always best, asparagus being easily spoiled if a strong bottom heat be given. I have no doubt but that spent tan would also answer well, as this gives a steady and prolonged gentle heat. A mistake is often made if stable manure is used, but of course if a large quantity be required hot water pipes would be preferable to any other method. A flow and return should be 
arranged under the beds, with the same running round the pits or house, and a very steady heat maintained, at first allowing only such heat as might be engendered by a little sunshine.

Time should be given for this work, for hasty forcing means weakly growths, and weakly growths mean a poor result. One of the best places to force asparagus slowly and well is in the tomato-house, and I know a good many market growers who have from three to twelve houses, each about ninety feet long, half unused during part of every year. Such houses are generally spanroofed, with beds on either side, and a walk, of course, through the centre. Some houses have borders about three feet wide, the pipes in some cases going round the houses, though in others running on either side of the walk. Here there is no bottom heat, and none is really required. Were these borders filled with wellprepared three-year-old asparagus plants, I question if anything would pay the grower better. Yet many people scarcely know what to put in their houses after the tomatoes are over, to occupy them till the houses are again required in the spring. To force asparagus thus is so simple that any novice when once instructed could do the work, as it is unlike any other crop with which I am acquainted. Nearly all market gardeners grow much the same things, hence gluts. Thus there is in the autumn a glut of chrysanthemums, all growers more or less complaining about the prices; and now that every one is growing narcissi and daffodils the same complaint is anticipated; but I think that to supply all our markets with forced asparagus till they become glutted is a consummation of the distant future. There is one great advantage possessed by asparagus, in that a valuable quantity can be packed and sent off in small boxes and hampers, the freightage being little in proportion to its value. This makes a considerable difference as com- 
pared with other crops of a more bulky kind. The greatest drawback is the time it takes to prepare the plants for this work; but when once well started on a large scale, the work is simple, and the results will justify the time and expense incurred.

To sum up, then, the principal points to observe in forcing asparagus.

Three-year-old plants, well grown, as shown in the illustration, should be used. Such plants should be taken up and placed in a very gentle heat, especially at the commencement, whether in frames resting on leaves or spent tan, or in pits of any length with the means of affording a little warmth, or in cucumber, melon, or tomatohouse, when such crops are over. No new soil need be added, the plants merely requiring to be covered a few inches deep, and when necessary lightly watered with tepid water, or with water about ten degrees warmer than the temperature of the house, pit, or frame. In any case do not use cold water, for although the plants will not admit of strong forcing they always respond to warm water.

I must here say that when such means as I have advised be employed to force asparagus, the plants are of very little further use ; in fact they do not pay to nurse for subsequent work. There is, however, another way of forcing, which consists, not in bringing the plants to the heat, but in bringing the heat to the plants. There are two notable places where this is done, one being His Majesty's garden at Frogmore, the other being Zion House Gardens.

In the former the beds are made somewhat after the style of ordinary out-door beds, but are bricked up at the sides, after the style of the old fashioned melon and cucumber pits. The spaces between, as nearly as I remember, measure from three to four feet, half the depth being filled with soil, and the top half provided 
with flow and return pipes for hot water. There are four or five such beds, and a boiler heats the lot. Frames with sashes are placed on these beds. I consider this an excellent plan for gently bringing the crops forward probably some two months before the outside crops come in. These pits, for such they really are, enable us to follow up our earliest forced produce, thus providing that no break occur for at least seven months in the year, which is a long enough season for anyone.

No doubt there are other means whereby asparagus can be forced; and anyone who undertakes this work should use the best and cheapest means, according to his materials. The point to bear in mind is that the future crop is in the crowns, and that if these be well developed by previous good culture, plants can really be crowded in the forcing bed, the roots requiring only a little soil and water at times. The future crop is in the crowns, just as the future bunch of grapes is in a well-matured bud, or the fine spike of lily of the valley in its plump bud. The real preparation is in providing for the development during the previous year. This point, I fear, is not always kept in view. Yet that it is recognised by some is shown by the splendidly finished asparagus which one sees at Covent Garden and other great markets.

\section{BUNDLING}

For the first few years, plants even crowded in rich land will give very fine asparagus, but this will not last for long, for the reason that the roots become entangled, and live by robbing from each other. I have known some people so ignorant of this matter, that when cutting the stems down in the autumn they select all berried branches and place them evenly over the beds in order to secure a quantity of young plants to grow up between 
the older ones. I need not say how wrong this is. No asparagus should be cut till the plants are three years old, and it is better to wait even a year longer than this. In Cornwall, under such treatment as I have advised, good asparagus can be cut when the plants are three years old. Still, I advocate for most counties another season's growth. I know that some people consider that the ground during this waiting period, should produce early potatoes or kidney beans, but nothing of the kind should be allowed. I said that when the manure has been put under, no more can be applied till the plants have run their race. This shows how absurd is the " snatching" of crops, which is advocated by some writers to satisfy their parsimonious clients.

Really, the plants will speak for themselves as to their fitness for cutting. If, after the second year of planting the shoots are half an inch in diameter, we may take it as an indication that all has gone well and that the plants are strong enough to cut from.

In two cases where my instructions were carried out, after the first season's growth, the plants attained the height of four and a half feet, and in the following spring, shoots three-quarters of an inch in diameter appeared, so that one of the growers cut liberally for several weeks but did not continue after the first of June. When I visited him in September of last year the plants had grown to a height of eight and a half feet, so that the cutting did not seem to have injured them.

As to the number of years that asparagus plants will live no limit can be fixed. I saw once some beds in a grand old garden in Devonshire which had a history of at least ninety years, and in Cornwall I know a bed, the proprietor of which is probably forty years of age, this bed having been planted by his father before the present owner was born, and yet it still produces splendid shoots which I have often exhibited to my 
audiences when lecturing. Indeed, having once prepared the ground and planted the stock, so little further attention is required that in these days of scarce and expensive labour I would rather be the possessor of an acre of asparagus than an acre of any other crop.

In the latest number of the "Royal Agricultural Society's Journal" (Vol. xi., part 4) is an article on asparagus by Mr John Norfolk of Wilburton, in which he says that "the time that cutting will commence must, of course, depend upon the season. About the middle of April would be the average time, though in some seasons there would hardly be any through before the beginning of May. It should begin as soon as any heads are one and a half or two inches above the surface, cutting all, both large and small with a proper asparagus knife-a sawedged one-as this kind of knife does not injure other crowns (shoots) as a sharp one would. The knife has a saw-edged blade about four inches long with a handle twelve to fifteen inches. The way to use it is to pass the blade down close by the head intended to be cut until the crown of the root is felt, then by a dexterous twist sideways detach the stem from the root (or crown). An experienced man should be employed to do this work, as a number of shoots are always rising at the same time in different stages from the same spot, and a careless cutter might destroy a great many. It is most important to keep the cutting well in hand. No hard and fast rule can be laid down about it, beyond that it must be done at the proper time. Two inches above ground is quite enough of growth, as if longer the plants begin to run and spoil their appearance in a few hours." I presume that $\mathrm{Mr}$ Norfolk means by this that the head would open and the compactness be spoilt. He goes on to say that as asparagus grows in length, the heads lose their plumpness and get thinner. It is only those who are accustomed to seeing asparagus growing who can 
realise the rapidity of its growth in hot weather when a whole cutting might run away in a day or two. At this period, therefore, it is important to put this work of cutting into the hands of practical and trustworthy men. Two inches above ground with six inches below (which will easily be obtained if the roots have been earthed up as directed) will be a good average market length. Mr Bunyard would by a recent pamphlet reverse $\mathrm{Mr}$ Norfolk's advice, as he would allow the stems to grow six inches or more out of the soil and cut level with the ground. I wish this could become the fashion. It would, I am sure, be better for the plants.

"The man who is cutting should pick up the heads as he cuts them, keeping them with the tops all one way till he gets a handful. He should then lay them down upon the bed, and thus proceed until the whole breadth is gone over. Another man should follow him with a basket and gather up all the heads, being careful to keep them straight. They should then be washed and tied ready for market. Women will do this work as well as and more cheaply than men. There should be a shed or building near by with a good supply of water. The best method of washing asparagus is to put a quantity at a time into a tub with plenty of water and give it a good swilling about-this will usually clean it. Take it out, place it on a table, and having sorted it in sizes, all the small is to be tied by itself, and the bestwhich should be about the thickness of a man's little finger-should be tied in bundles of six scores each. The bundles may be tied with willow withes, or with good raffia. But whatever is used must be strong enough to bind safely. The bundles must be made flat, not round.

They should be about seven inches wide and four inches through, larger or smaller, according to the size of the asparagus. The old method of tying was, first, 
to tie six small bundles of a score each, then to lay two of these bundles side by side with tying material under them, to put two others on the top, and one on each side, and then to bring the tying material round and fasten.

But the newer and quicker way is to tie the whole bundle at once. To do this two pieces of board should be fixed edgeways upon the table to hold the asparagus in position, in order that the tie may be placed under it. These boards (or the frame as I call it) must have a cut down to the table in which to lay the tying material. Two ties are necessary, as otherwise the bundle would not be made flat as desired. A small one should first be laid down the middle of the board or frame lengthwise as the asparagus lies. Then place across and in the cuts before mentioned the willow which is to go round the bundle. The smaller willow, running the same way as the asparagus, should now be bent and its two ends brought upwards to form a loop below the tying willow. The six score must now be counted and laid straight and neatly in the frame, placing half the number on either side of the two ends of the willow running longways. Now bring the tying willow round between the two ends of the other willow, draw tightly and fasten, still keeping the bundle in the frame, then take the two ends, press the bundle flat, and tie them round the top willows, thus holding the two sides of the bundle together and keeping it flat. Fairly good asparagus eight inches long should weigh three to four pounds a bundle, being an average size for market.

After the bundles are tied they should have a good swill through clean water before being packed. The best baskets to pack in are common bushel flats with lids, and these hold eight to ten bundles each. The asparagus should be placed with the butts to the end of the baskets, and the crowns towards each other 


\section{THE BOOK OF ASPARAGUS}

in the middle. The flats would be large enough to take two bundles in length, with a little long grass between to prevent the heads from being broken."

These remarks of Mr Norfolk's are quoted to show the practices generally adopted. In a great measure I agree with the advice, but I can scarcely understand first-rate asparagus being the "size of a man's little finger." Then in the matter of washing, I feel sure it would be better not to follow the treatment suggested. Asparagus, like washed potatoes, looks well for the hour after being washed, but a little earth or dust on the stems does not detract from but rather improves the appearance. All vegetables washed long before the cook requires them are somewhat spoiled. Personally, I do not cut the ends off, not using the saw knife.

\section{MARKETS}

When lecturing I am asked about marketing produce of all kinds more than about anything else. To many it is one of the most important matters, especially to those who grow first-class produce to catch and not lose the markets. To all growers of vegetables for sale I commend a paper called the Fruit Grower, Fruiterer, Florist, and Market Gardener, in which every week is published a list of the best buyers or salesmen.

And it is important to study suitable markets, for I have seen excellent produce which would be well received in Covent Garden go begging where quality was not appreciated, and cheapness was the only recommendation. I was told the other day by a grower that at Christmas he could only get three shillings a bushel for sound, well-coloured Blenheim orange apples, there being so many foreign ones for sale. I showed him a copy of the paper referred to, and he will in future sell to more advantage outside his own county. A district 
manufacturing cloth will send cloth all over the world. In like manner the horticulturist should send his produce to places where it is wanted and appreciated.

Such points should be better understood and acted upon. The question of markets should be less of an enigma. Another important point is, wherever the climate favours such things as asparagus, there should be grown the earliest available supply. Did every county in England avail itself of its capability according to respective resources, much of the foreign produce now imported would not be needed.

\section{Insects and Diseases}

Few plants escape disease as does properly grown asparagus, and probably what disease it is sometimes subject to is traceable to unnatural treatment. Deep and heavy earthings-up I consider to be a frequent reason that plants become unhealthy with a kind of rust. I am told that some years ago asparagus was extensively cultivated in the Penzance district until a disease of this sort visited the plants. Few growers now continue its cultivation, but I am growing it successfully there, though I do not intend earthing up eight to ten inches or more, as I am told was the custom.

The greatest pest to the crop of which I know is the asparagus beetle (Crioceris Asparagi). When this pest visits the plants it does a good deal of injury, eating the rind or outer portion of the stems, and quite stripping the plants. It is not an easy foe to deal with, but I have used the following means, and when I have followed it up several times, have succeeded. Paraffin and soap makes one of the best as also the easiest of insecticides, and larger or smaller quantities of either ingredient might be safely used if properly made, which means properly churned. A good mixture for this plant can be made with five 
pounds of soft soap to three quarts of paraffin, adding water to make sixty gallons of material for syringing. The soap must be boiled till well dissolved in two gallons of water, then in another vessel put three quarts of paraffin and pour the soap water on it. With a whisk, made of a handful of small sticks, well stir rapidly for ten minutes, when it will be mixed. Some advise the syringe to be used for this purpose, but I have never been able to do this, as it becomes too hot to handle properly. If I wish to use this at once, I add the water to make the sixty gallons. If syringed over the diseased plants at a temperature of eighty degrees, it will be more effectual than when cold.

There are many similar washes. The Board of Agriculture, 4 Whitehall Place, London, issues leaflets free, bearing on this and other obnoxious insects.

Paris green and lime forms another mixture, but this is a poison, whereas the former kills by contact. If this be used, however, take of Paris green one pound, lime one pound, and one hundred and sixty gallons of water. The lime must be carefully slaked before mixing, so that every particle of it is well and thoroughly powdered before mixing with the water, or the syringe will become clogged. The reason that lime is necessary is that Paris green is insoluble, and will quickly settle, but the lime somewhat prevents this. The Paris green is a very fine green heavy powder, and when coming in contact with the lime in the water mixes somewhat with it. Still it must be continually stirred when using, or it will settle at the bottom of the vessel.

I have also used dry wood ashes and sawdust mixed well together with paraffin at the rate of two bushels of ashes, one bushel of sawdust, and one gallon of paraffin. When the plants are wet, sow over them this mixture, repeat several times, and, if it adheres, this beetle will disappear. 


\section{Summary of some Important Points}

I. If you decide to raise asparagus from seed, go to a reliable seedsman. Poor seeds mean a season (or even more) wasted.

2. Sow on rich, clean land of a light loamy nature. Sow thinly. Keep free from weeds.

3. Plant in March in good, wide trenches. Use oneyear-old plants for making permanent plantations. Do not let the sun or the wind have even a look at the roots.

4. Make no attempt to snatch a crop of potatoes, or even of saladings, from a young asparagus plantation.

5. Place stakes so that the growing stems may not be blown down and the plants be thereby weakened.

6. Manure freely as directed.

7. Do not earth-up unduly, but strictly follow the directions given in this book.

8. Select well-drained land facing south, when this is available. 


\section{THE ASPAR AGUS}

\section{AS A DECORATIVE PLANT}

THE English kitchen-garden during the months of summer contains many objects of great beauty-gourds, climbing beans, globe artichokes, and the rest-but nothing more graceful than the feathery growths of the edible asparagus. Indeed, this useful plant is fully as handsome to the eye as it is delicious to the taste, and few pot plants look brighter and more attractive at Christmas than young bushes of the common asparagus obtained from seed sown when ripe in the autumn and "brought on" in a warm greenhouse.

But there are many other species of this genus which are well worth growing for their beautiful foliage and habits. Mr Baker's "Monograph of Asparagacex," contained in the fourteenth volume of the "Journal of the Linnean Society," gives a total of ninety-seven species, but only a few of these have yet become at all well known in England. Most of them are somewhat tender and can only be grown in this country under glass, but a few are hardy. In his "A Gloucestershire Garden" Canon Ellacombe says that he grows Asparagus acutifolius in the open, though apparently against a protecting wall. This is an evergreen climber, with short, hard, bristly leaflets, growing to a height of four or five feet. It is to be seen growing wild and in abundance along the rocky shores of the Mediterranean. Canon Ellacombe also grows in the open the beautiful and vigorous $A$. verticillata, a deciduous species, and the well-known 


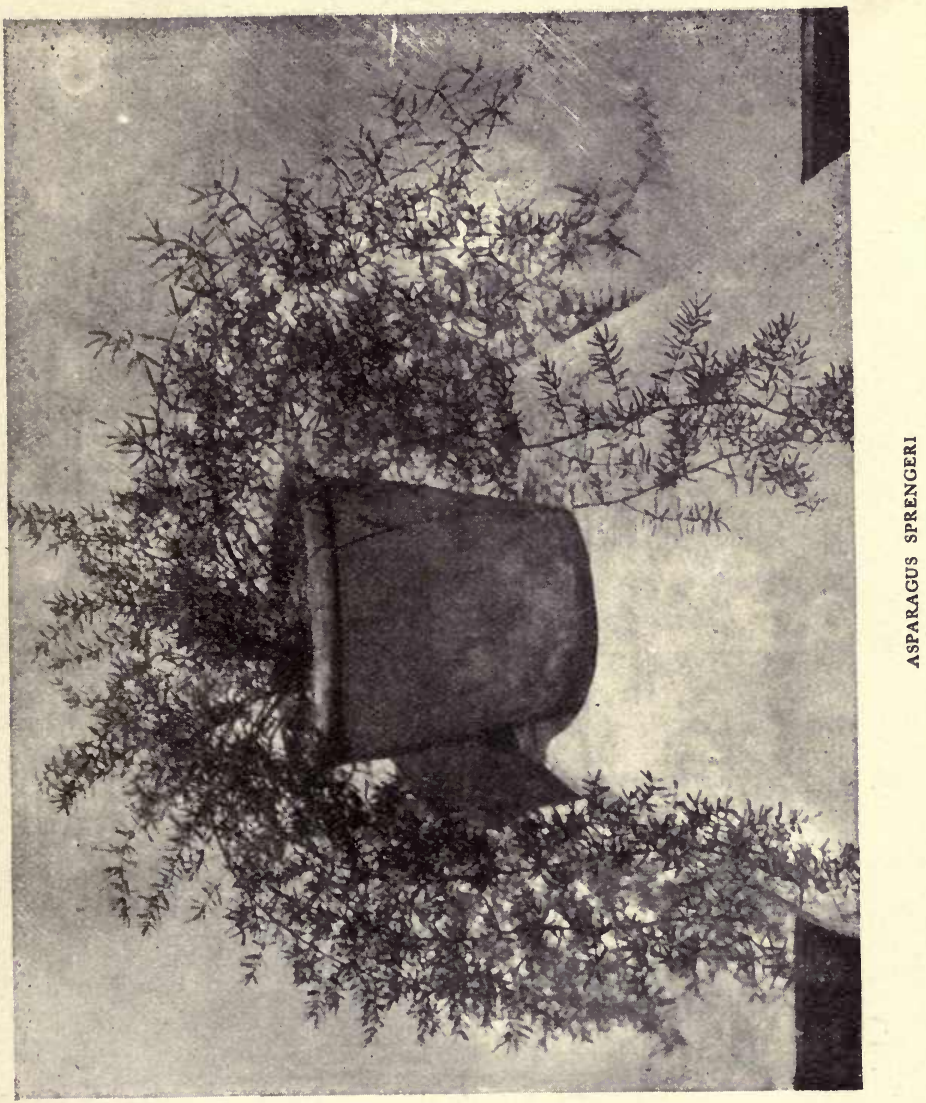


LIBRAR
OF THE

UNIVERSITY

CALIFORNIA 


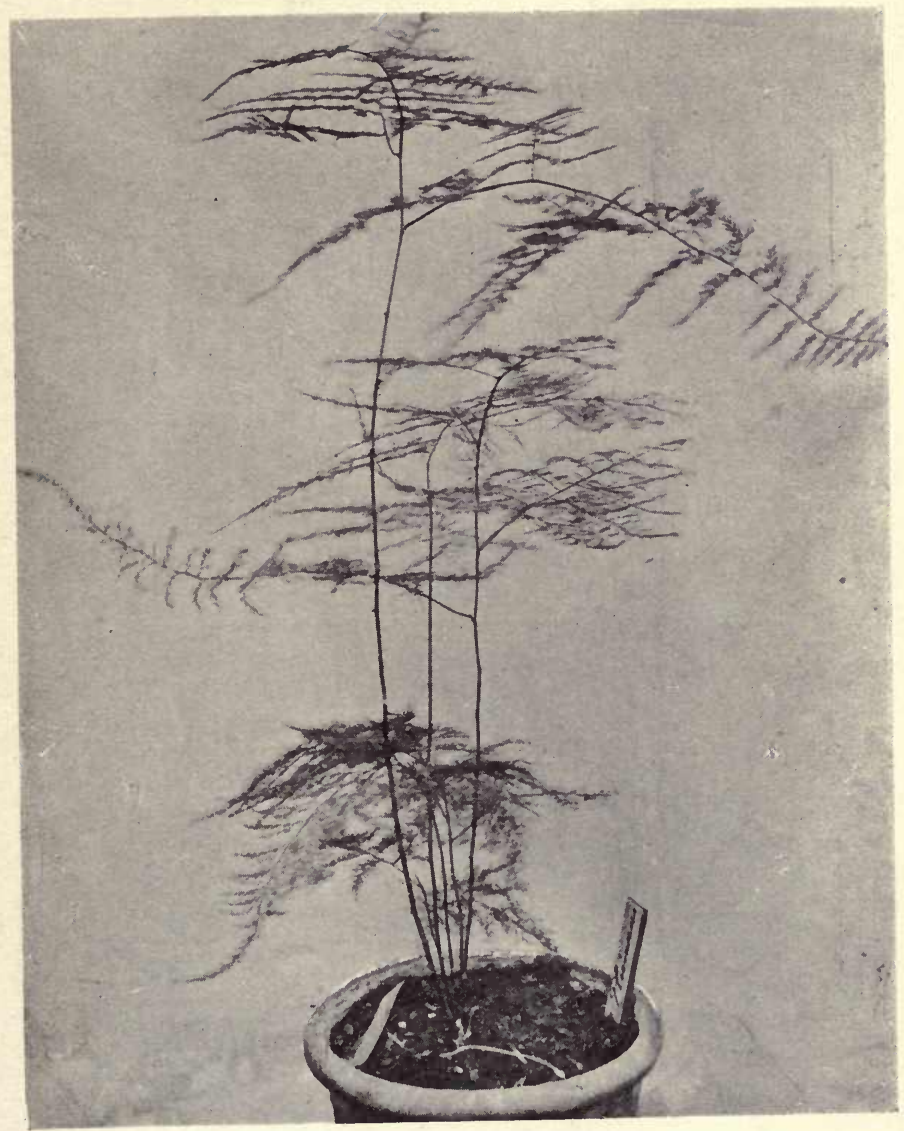

ASPARAGUS PLUMOSUS 
LIBRARY
OF THE

UNIVERSITY

CALIFORNIA 
(as a greenhouse plant) A. medeoloides. This has long been grown in England, and is described in Mawe's "Universal Gardener" as well as in Hanbury's "Complete Body of Planting." Both these authors advise that it be removed to a warm greenhouse in the autumn in order that it may be in perfection at Christmas time. Hanbury, in particular, gives a good and interesting description of the plant:-

"The Myrtle-leaved Climbing African Asparagus admits of two principal varieties called the Broad-leaved and the Narrow-leaved. The root of the Broad-leaved is composed of several oblong, fleshy knobs, which unite at the top. The stalks are weak, climbing, divide into numerous branches, and will rise, if supported, to the height of about five feet. The leaves are pinnated and single; the folioles are oval, spear-shaped, pointed, sessile, of a dark but glossy green colour on their upper side, but paler underneath, and are placed alternately along the midrib. The flowers come out from the sides of the branches on short foot-stalks; they are of a dull white colour, appear in October, and are of ten succeeded by ripe heart-shaped seeds in the spring. The Narrowleaved sort differs from the other inasmuch as the stalks are smaller and less branching. The leaves are long, narrow, and of a greyish colour. The flowers are of a greenish-white colour, but are produced like the former; they appear about the same time, and the seeds ripen accordingly. The stalks of both these kinds die to the ground every summer, but fresh ones spring up in the autumn, and continue growing and exhibiting their flowers all winter."

Among other kinds which are hardy in warm, light soils is the very beantiful $A$. brousseroneti.

One of the first of the greenhouse asparaguses to be introduced into England was $A$. retrofractus, which was brought from the Cape in 1759; but, owing to the fact 


\section{THE BOOK OF ASPARAGUS}

that it rarely if ever flowers here, and can be increased only by the slow process of layering, it never became a very popular plant. About 1890 an attempt was made by $M$. Lemoine to popularize it and met with some success, for since then it has been more commonly grown than ever previously. It likes sunlight but not too much heat, and it also likes plenty of pot-room. If kept in small pots, however, pretty little plants for table decoration may be obtained. Grown liberally, $A$. retrofractus is a tall woody species, with thin leaves upwards of two inches in length, produced in tufts from the branches. The crooked stems are usually covered with a grey powder, which gives a characteristic appearance to the plant. Another species long since introduced from the Cape is $A$. scandens, which climbs to a height of ten or more feet, the whole plant being a dense mass of rich green foliage. The curved leaves a little resemble those of $A$. Sprengeri in texture, but, being arranged in one plane, give somewhat the appearance of a coarse variety of $A$. plumosus. $A$. scandens is increased by division, rarely ripening seeds in England -hence its comparative rarity. This cause, however, does not explain the reason that $A$. deflexus is not more grown, for it seeds abundantly, and is also easily increased by division of its underground rhizome, which spreads at a great rate. It is a tall vigorous plant, with wiry stems and bright green leaves. $A$. umbellatus from Madeira is also a beautiful climber worthy of more general cultivation.

The three species which are by far the most frequently grown in our rooms and greenhouses are $A$. sprengeri $A$. plumosus, and $A$. tenuissimus. It was only ten years ago that Herr Sprenger, who collected for Messrs Dammon \& Company of Naples, introduced the firstnamed of these species from Natal. It has become thoroughly popular — and deservedly so - as a room 


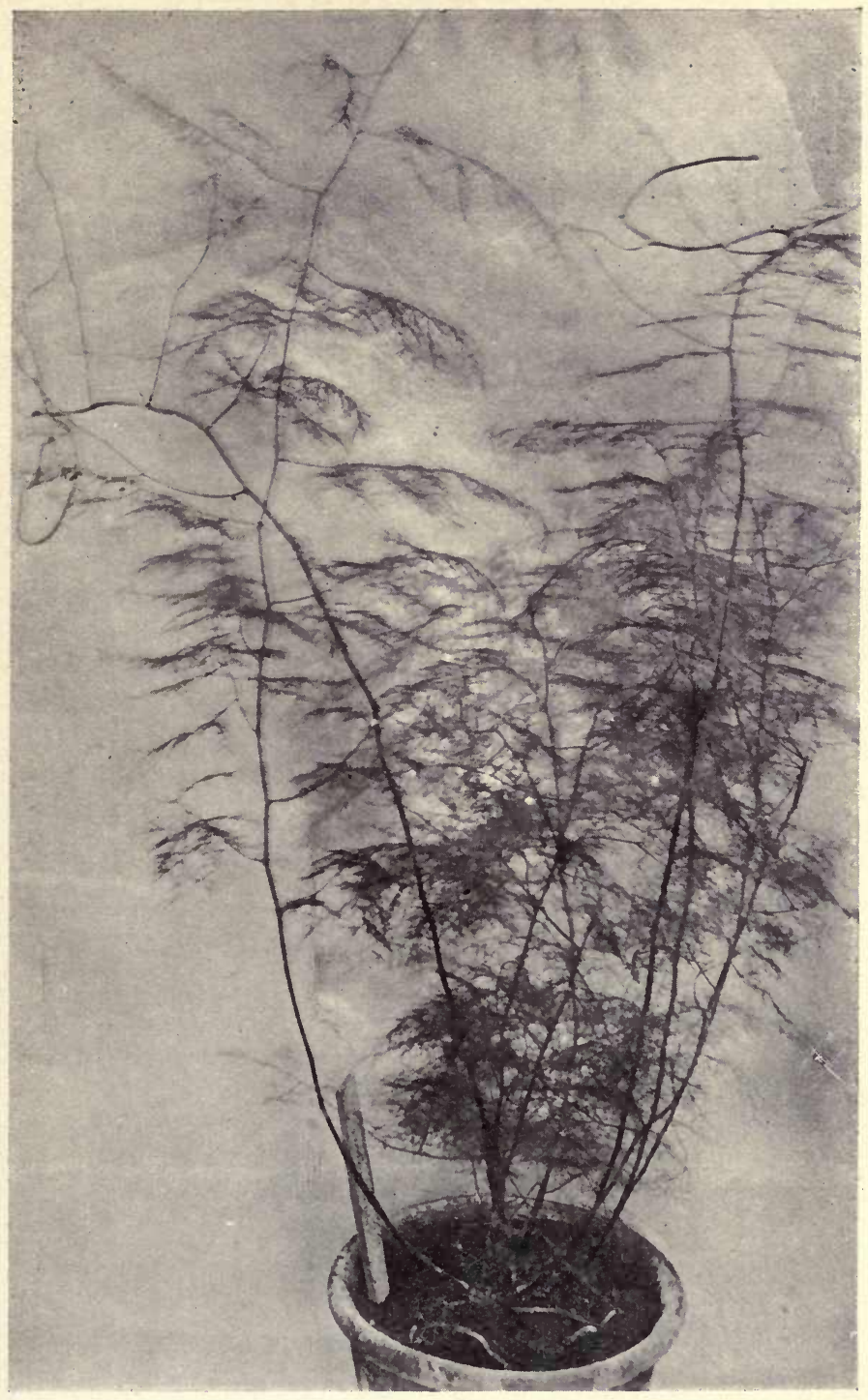


lIBRARY
OF THE UNIVERSITY OF 
plant, and as a plant for the cool greenhouse and for the stove-for it possesses beauty of foliage, flower and fruit, is easily multiplied by seed or division, and, provided it has rich loamy soil, ample pot-room, and plenty of water, is a rapid and vigorous grower, making growths of six feet or even longer. The flowers, which are borne in abundance under favourable conditions, are white and possessed of a pleasant fragrance. The Royal Horticultural Society gave an Award of Merit to the variety Compacta in I898.

Asparagus plumosus and $A$. tenuissimus somewhat resemble one another in the light and fragile character of their stems and foliage, and also in the treatment suitable for their growth and health. Both may be readily multiplied either by seeds or by cuttings. To effect the latter, take off the young side shoots close to the old stem to a butt of about four inches, from April to June, and place in light soil in a close propagating case. Both $A$. tenuissimus and $A$. plumosus may be kept for some time as dwarf compact pot plants by cramping their roots in a small space, but given room they both produce long shoots and develop individual character. In $A$. plumosus cristatus each branchlet ends in a divided crest after the style of the crested ferns. All the species of asparagus like abundance of light, and although, like the garden $A$. officinalis, they are mostly long-suffering, they yet well repay generous and careful treatment. 


\section{HISTORY AND COOKERY}

IN the "Gentleman's Magazine" for January, I 793, is a review of a book entitled "The Benefit of Starving; or, the Advantages of Hunger, Cold, and Nakedness; intended as a Cordial for the Poor, and an Apology for the Rich." When one realises how little use we make of our opportunities, he can but fancy that every one has taken this book to heart and decided to live up to its title. Otherwise it is hard to conceive why it is that so easily cultivated a vegetable as asparagus is still an expensive luxury; or why it is that such simply grown delicacies as salsify and scorzonera are still so little known in England. In the course of a very amusing article, James Payn once pointed out how delightful it would be, when called on by folks whom we did not wish to know, to return them this by post: " $\mathrm{Mr}$ So-and-So's compliments, but he knows a great deal too many people already;" and this is the sentiment which most people seem to feel towards vegetables and fruits which were not given to them in their childhood.

Asparagus, however, is no novelty, being, indeed, one of the oldest of cultivated vegetables. Cato the elder discussed the culture of asparagus at length, and Pliny referred to it as worthy of the gardener's tenderest care. In his eleventh Satire, Juvenal speaks of it as one of the dishes for his feast: "Montani Asparagi, posito quos legit villica fuso." This, of course, refers to wild asparagus, probably the same species as that which we now cultivate, and which is still found wild at certain spots on the coast of Wales, Cornwall, Dorset, and the Channel Isles-most notably on Asparagus 
Island, near the Lizard Point. It is even said to be commonly found in the Elysian fields. For many hundred years, however, it is as "cultivated asparagus" alone that the plant has been seriously related to culinary art; and Meager, writing about I680, says that even then abundance of forced asparagus was to be obtained at the Central London Market. Gerard and Parkinson have each something to say of the vegetable, and Evelyn, in his "Acetaria," reports the high opinion which his contemporaries had of it: "Next to flesh, nothing is so nourishing as asparagus." This, unfortunately, is not a verdict which we can support in these days of physiological and chemical research. As showing the composition of $t$ wo vegetables typical of those dealt with in this book, the following table (after König) may be of interest :-

Celery. Asparagus.

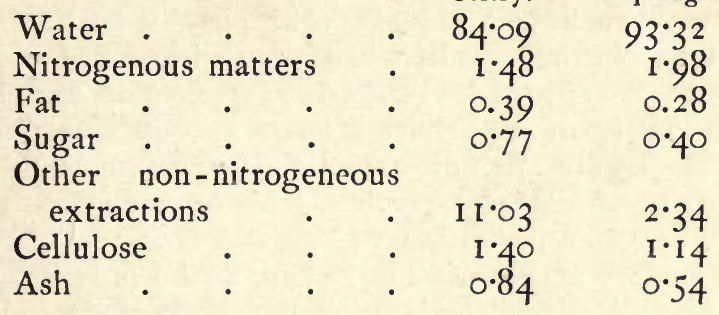

Constituents of the Ash

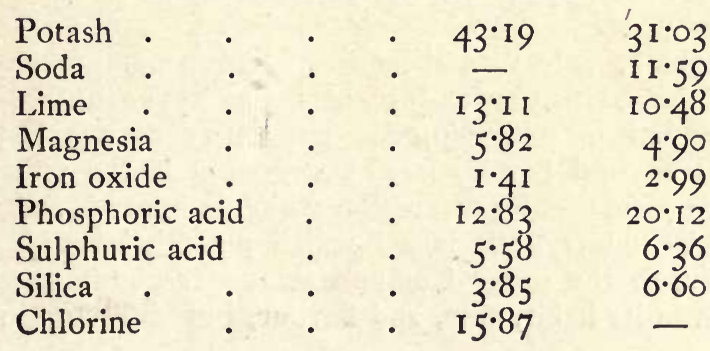


It is not, however, because of their nourishing value that these vegetables are so important, but because of their mineral salts and agreeable flavours, the value of which cannot be over-estimated on physical as on æsthetic grounds. Moreover, in a cooked state, celery, asparagus, seakale, scorzonera, and salsify are all extremely easy and quick of digestion, even though they do not possess quite so many virtues as some old writers have thought, from Anthony Mizold, who, thirteen hundred years ago recommended asparagus as a certain cure for toothache, down to quite recent editions of the British Pharmacopeia.

Of the plants just named, the asparagus makes the strongest appeal to our sense of the beautiful. This is what we should expect from its botanical relationship, for it belongs to the order of beautiful plants known as Liliaceae, to which belong also our lilies, scillas, tulips, and fritillaries. The garden asparagus ( $A$. officinalis) is, as everyone knows, a herbaceous plant with tiny scaly leaves, from the axils of which proceed bunches of little needles usually and erroneously spoken of as leaves. It bears small bell-shaped flowers containing honey. These flowers are uni-sexual, male and female flowers occurring on different plants. The male flowers, however, contain a rudimentary pistil, and the female flowers rudimentary stamens. The honey, which is secreted at the base of the petals, is accessible to bees; for whose benefit, also, the pleasant scent of the asparagus flowers is produced.

Seakale, celery, and salsify, like asparagus, occur wild in England; and seakale has never until lately succeeded in extending its popularity as a vegetable much beyond these isles. Scorzonera is the only one of the plants under discussion which is never found wild in this country. It is a Spanish plant belonging, like salsify, to the order Compositæ, and resembling salsify much in its habit, size, and flavour, but differing in the 
colour of its root, which is dark brown. It is, compared with salsify, a new vegetable to cultivation, for, whilst the latter seems to have grown in ancient Greece, and was referred to by Olivier de Serres in the sixteenth century, scorzonera does not appear to have been grown in gardens for much longer than a century. Celery is another vegetable with a history, for it is mentioned by Homer, and even as a cultivated vegetable by so ancient a writer as Pliny. It is one of those vegetables which is but half used, for, although popular, it is served in England usually in but one or two ways, whereas it lends itself to the utmost variety according to the art and ingenuity of the cook.

"Gross are they who see in eating and drinking nought but grossness. Gluttony is a vice only when it leads to stupid inartistic excess." So writes Mrs Pennell in her delightful "Feasts of Autolycus," a book known and treasured by everyone who appreciates "fine" eating and tasteful menus. The importance of the subjects of food, cookery and digestion, has always been recognised, as is illustrated by such proverbs as: "A good cook keeps out the physician," "Better dinners, better tempers," "Wisdom proceedeth neither from him who is hungry nor from him who is full," "Diplomacy lieth under the dish cover," and the like. Indeed, there is much wisdom in the saying of BrillatSavarin that "of all the bodily functions, digestion is that which has most influence on the morale of the individual -his feelings and mental condition."

Once, no doubt, man had such difficulty in obtaining from nature the flesh and fruits needed to ward off starvation, that when a stroke of luck brought him deer or other beast he settled down to feast to utter repletion, knowing not when such a meal might again come his way. Many people seem to cling to this old tradition even now, and our big dinners and banquets-though 


\section{4

more sensible than formerly-still are composed of such quantities of foods and such numbers of courses as to make artistic feeding an impracticability. A tasteful frugality rather than a wasteful, tasteless and ridiculous excess is the aim of those with any claim to the title of artists in practical life. Instead of eating, as the Duchess of Orleans, writing in 1718 , said she had often seen the king eat, "four plates of different kinds of soups, a whole pheasant, a partridge, a dish of salad, two thick slices of ham, mutton flavoured with garlic, a plateful of pastry, and finish his repast with fruit and hard boiled eggs," a man of taste will - select from one to three dishes, and on the proper preparation of them will cause to be expended the energy and intelligence which would in the alternative have provided the ponderous and illcomposed meal of the inartistic.

But in the arrangement of meals and the cookery of food things move slowly, and writer after writer has copied his predecessors, with only such rare exceptions as that great original cook La Varenne, who wrote in I653, and perhaps a dozen others who have studied things for themselves. Thanks to America, thanks to France, and thanks also to certain reforming spirits in England, we are at last on the way to a revolution in dietetics. Meat is losing its all-pervading power, and the value-even the sufficiency-of a vegetable diet is becoming a matter of common belief. The vegetables with which we are now concerned are not among those which can in any sense replace meat as an article of food, but their importance both from a hygienic point of view and also from the standpoint of pleasure in eating cannot be over-estimated.

In a very interesting little book called " A Treatise of all Sorts of Foods, both Animal and Vegetable : also of Drinkables," "written originally in French by the learned M. L. Lemery, Physician to the King," publishę 
in an English translation in I745, it is amusing to read that " the essential Salt which is contain'd in Sparagrass in a sufficient Quantity, is very proper to penetrate into all the Recesses of the Parts, there to dissolve the glutinous and embarrassing Substances they meet with, and to make a passage into all the Pipes, by breaking and removing the Obstacles that are in their Way. Sparagrass in Latin is called Asparagus ab aspergendo, sprinkling, because 'tis convenient to water them." We don't, of course, accept all that as gospel nowadays, but without exaggeration it may be affirmed that there is much real hygienic virtue in asparagus, and also in the other vegetables we are now considering.

The directions given for the cooking of asparagus have not varied much for many hundred years. Thus in " L'Ecole des Ragouts, ou Le Chef-D' Euvre du Cuisinier, du Patissier, et du Confiturier," of which the thirteenth edition was published at Bordeaux in 1695, the following directions for boiling and serving asparagus are given:- "Pour bien faire cuire des asperges entieres, mettez-les dans de l'eau boüillante avec un peu du sel, et quand elles seront attendries moderement, il les faut retourner, et ayant tiré le chauderon hors du feu, laissezles refroidir à demi, puis les tirez hors de l'eau, et les faites égouter, les couvrant d'un linge blanc, puis on les mettra dans la sausse suivante.

"Mettez un plat sur un bon feu avec ce qu'il faudra de vinaigre, et du sel, et un bon morceau de beurre; vous y pouvez ajoûter un peu de poivre, il faut tourner le beurre jusqu'à ce qu'il soit fondu, afin que la sausse soit liée : Puis on y mettra les asperges, vous pouvez y raper de la muscade par dessus: Un peu de grosse chaplure de pain est bonne dans cette sausse, et même du jus d'éclanche, ou d'autre viande rôtie. Au lieu de faire cette sausse, on se contente de manger les asperges avec de l'huile, du sel, et du vinaigre comme une salade," 
In a very amusing book titled "Les Dons de Comus," of which a "Nouvelle Edition" was published in 1758 , numerous recipes are given for the cooking and dressing of asparagus: Asperges au beurre, Asperges à l'huile, Asperges au jus, etc. The directions given for asperges au jus are these:-_" Etant cuites et dressées, vous servez dessus un peu de blond de veau, dans lequel vous aurez mis un peu de beurre manié."

Where most of the old writers and cooks failed was in fixing too short a time for the adequate cooking of the stems-this being inevitable when the old plan of immersing the asparagus entire in boiling water was followed. Thus "La Cuisiniere Bourgeoise," published about $175^{\circ}$, names "un demi-quart-d'heure" as the correct time, and even Gouffé directs the cook to boil for ten minutes only.

As the result of numerous experiments, the following simple directions are offered as conveying the principles to be observed in cooking asparagus entire to be served as an entremet:-

Having carefully scraped and washed it, take the asparagus, and resting it loosely heads downwards on a table tie it in a bundle of twelve to twenty-four sticks with tape and cut level the base of the stems. In this way the sticks will be all of the same length, and will all be cooked at the same time. Set the bundle thus formed upright in a saucepan containing enough boiling salted water (quarter ounce to one quart, with or without a tablespoonful of vinegar) to cover about two-thirds of the height of the asparagus, the tender tips so commonly spoilt by over boiling being thus cooked by steam alone, whilst the tougher stems are properly cooked in the boiling water. An appliance for the proper cooking of asparagus has been designed by a member of the Cornish Craft Guild, Hayle, and may be obtained at the price of two shillings. The time of cooking varies slightly 
according to the freshness (asparagus should be cooked on the same day that it was growing in the garden) and variety of the asparagus, but as a rule the time may be taken at from thirty to forty minutes, the cover of the saucepan being left off during the whole time. When cooked, the stems should be tender, but not flabby. Mrs Glasse, in her celebrated "Art of Cookery," advised to "cut the round of a small loaf about half an inch thick, toast it brown on both sides, dip it in the asparagus liquor, and lay it in your dish; pour a little butter over the toast, then lay your asparagus on the toast all round the dish, with the white tops outward," and her advice has been copied by nearly every cookery writer-English and American - since her day. Much the nicer way, however, of serving boiled asparagus is to drain it thoroughly, remove the tape or riband, and place the vegetable on the drainer of a hot asparagus dish or ordinary vegetable dish, on dry unbuttered toast, or, as Gouffé suggests, on a napkin.

Dr. Kitchener, in his "Cook's Oracle," did indeed advise that one should " pour no butter over them, but send some up in a boat, or white sauce." Better than white sauce or melted butter as an accompaniment to boiled asparagus is sauce Hollandaise, or (as Mrs Roundell suggests in her excellent " Practical Cookery Book") the beurre fondu of the Dutch. This is made by melting four ounces of butter in a saucepan, adding a saltspoonful of salt, a pinch of mignonette pepper and a squeeze of lemon juice. Let this settle over the fire. and before the butter has quite liquefied, take the saucepan off, and let the heat of the saucepan complete the melting. In this way the butter will be creamy, and not like oil. Pour the sauce free from sediment into a very hot sauce-boat, and see that the plates for the vegetables are thoroughly hot.

Sauce Hollandaise may be made thus :-Put in a bainmarie two and a half ounces of butter and beat it to a 
cream. Add a large saltspoonful of salt, a small pinch of mignonette pepper, three tablespoonfuls of vinegar, and a tablespoonful of hot water. Place on the fire, carefully avoiding the boiling point, and stir with a wooden spoon until the mixture becomes a thick cream. Then remove and serve.

To be cooked entire as a separate and distinct dish will usually be the fate of asparagus in the kitchen of the epicure, but there are many delightful combinations into which " the queen of vegetables," as Soyer called it, need suffer no loss of dignity in entering. Eggs especially seem fitted to take share in these partnerships. The possibilities are infinite, the following being but a selection of two or three most simple and satisfactory.

\section{Eggs and Asparagus served on Toast}

Boil a bundle of twenty to thirty heads of asparagus, and, having well drained it, cut it into small pieces about a quarter or a half of an inch in length. In a stewpan mix three well-beaten eggs with an ounce of butter and a little pepper and salt. Do not let this mixture boil, but heat it sufficiently to thicken the eggs. Stir in the asparagus, and in about one minute spread the mixture on rounds of buttered toast. A little cream may be added to the mixture, and bread fried in butter may be used instead of buttered toast.

\section{Asparagus with Hard-Boiled Eggs}

A sufficiency of asparagus having been boiled as directed, it is to be laid on a hot dish or napkin and surrounded by hard-boiled eggs bisected lengthways, and placed flat sides upwards. This pretty dish requires no sauce, though melted butter may be used with it. It is, however, best suited to be eaten with well buttered bread or with cold tọst buttered. 


\section{Baked Asparagus with Eggs}

Boil a bundle of twenty to thirty heads of asparagus, and, having well drained it, cut it into small pieces about a quarter or a half of an inch in length. Put the asparagus with an ounce and a half of butter and a little pepper and salt into a stewpan. Heat the mixture and pour it into a buttered baking dish. Beat six eggs and mix them with a little salt and pepper and an ounce of butter, stirring in also an ounce and a half of cream or rich milk. Pour this mixture over the asparagus in the baking dish, and place in the oven until the eggs are cooked. A much simpler way, though one by no means so satisfactory, is to place the cooked asparagus into a buttered baking dish, break the eggs on top, and cook until the eggs are set. Mrs Marion Harland, in her "Common Sense in the Household," published in New York in 1885 , strongly recommends a dish which she calls "Asparagus in Ambush," but this is simply the "Asparagus forced in French Rolls" of Mrs Glasse and her numerous copiers (one finds her recipe reported almost verbatim in Henderson's "Housekeeper's Instructor" and the other popular cookery books of the same period), which, though a pleasant enough dish, represents an act of sacrilege against so subtle a thing as asparagus. It consists in cutting off the tops and scraping out the crumb from some stale rolls, setting them in the oven till crisp, filling them with the following mixture, replacing the top, and setting again in the oven for three minutes, the rolls to be eaten whilst hot. The mixture is made by boiling a pint of milk and beating into it four whipped eggs, stirring over the fire till it thickens, when should be added a great spoonful of butter, a little pepper and salt, and the tender tops of fifty heads of asparagus, cooked and minced. Directly 
the asparagus is added, take the pan from the fire and fill the rolls with the mixture.

Mrs Roundell quotes an interesting recipe for

\section{Asparagus à la Chateau-roux}

Boil some asparagus in the manner advised, dry it carefully, keep it hot, and pour over it a sauce made of one ounce of butter thickened with the yolks of two eggs well beaten, a squeeze of lemon, and a little pepper and salt. Be careful not to use any of the whites of the eggs, and heat the sauce in the bain-marie.

From Italy we obtain two recipes of some value, one, of course, being for

\section{Asparagus with Cheese}

In England we use cheese too infrequently in combination with vegetable products, but those familiar with baked potatoes and cheese, boiled rice and cheese, oatmeal and cheese, and similar dishes, will always approach any such new combination with interest. Boil a bundle of asparagus, place it in a fire-proof china dish, sprinkle with a little pepper and salt, and place on it two ounces of butter. Heat carefully over the fire for ten minutes, and, sprinkling with a thick layer of rather dry Cheshire or Cheddar cheese (the Italians and unpatriotic English use Parmesan), heat for two minutes longer and serve in the pan used for cooking it.

Another

\section{Italian Way of Cooking Asparagus}

quoted by Mrs de Salis, in one of her excellent little books, consists in taking some asparagus, breaking it 
into pieces, boiling them and draining off the water. Take a little oil, water, and vinegar, let it boil, season it with pepper and salt, throw in the asparagus, and thicken with the white of eggs.

\section{Sweet Asparagus Stew}

A nice way to utilise thin asparagus is to remove the white parts from a bunch and divide the green tops into inch lengths. Throw them into a stew-pan of boiling water and boil for ten minutes. Pour off the water, leaving about a quarter of a pint, add an ounce of butter, a teaspoonful of sugar, and a little pepper and salt. Cover the pan, and stew for twenty minutes. Then thicken with the yolk of an egg and a little cream, and serve on toast.

A much tastier dish is that given by Gouffe under the heading

\section{Asparagus Peas}

a very similar dish to the "Asperges aux petits pois" of the old "Cuisinière Bourgeoise." Slightly modified, the directions are these:-Take some green asparagus tops and break them into pieces about a quarter of an inch in length. Boil them in water till cooked, then drain them on a cloth and put them in a frying pan with-for each pint of asparagus tops-two ounces of butter, a teaspoonful of pounded sugar, and a little salt. Then thicken with the yolk of an egg, an ounce of butter, and a tablespoonful of cream. Toss over the fire till the butter is melted, and serve in a hot dish.

The following is as satisfactory a recipe as any for making 


\section{Asparagus Soup}

Take a bundle of about twenty heads, cut off to a length of half an inch the green tops of half of them and put them aside. Place in a large stew-pan a quart of milk and water or stock, an ounce of butter, a finely divided lettuce, a little salt and pepper, two or three moderate sized onions sliced, a strip of celery, a bunch of herbs, and the asparagus. Boil for an hour and then strain. Pound the residue and rub it with a wooden spoon through a hair sieve. Mix together this pulp and the strained liquor, adding half a pint of cream, the yolks of two or three eggs, and a few drops of tarragon vinegar. Stir over the fire till it thickens, but do not let the mixture boil. The asparagus tips, having been boiled separately for about five or ten minutes, are to be added to the soup when it is poured into the tureen.

These are but a few of the many ways in which asparagus may be used to tickle the palate of the sensuous, but the wise will beware of too elaborate combinations in which the character of the vegetable will certainly be lost, as it must inevitably have been in that composite stew described by Dickens as produced at the Jolly Sandboys. There is, however, one other culinary use of asparagus which we dare not pass over, namely, its use as a constituent of salads. Sir Henry Thomson has said that "cold boiled asparagus served with a mayonnaise forms a dish of its kind not to be surpassed." Soyer said that sauces are to cookery what grammar is to language, but even mayonnaise is as often mangled as made. Yet its making is simplicity itself :Beat in a soup-plate the yolk of one egg, adding drop by drop one tablespoonful of salad oil. Then add another tablespoonful of oil and mix well, after which another may be added. Incorporate gradually a small teaspoonful 
of vinegar or lemon juice, a few drops of tarragon vinegar, a very little cayenne and half a teaspoonful of salt. Immediately before using the mayonnaise, add half a teacupful of cream whipped very stiff.

Instead of mayonnaise, however, plain French dressing may be used with cold boiled asparagus with equal or even finer effect. In mixing a French dressing one must carefully avoid the errors which Sydney Smith was so proud of making, that he tried to render them immortal in verse. We shall scarcely copy him in adding anchovy sauce to our dressing, but we may easily be led to follow his proportions-which are far from good ones. The correct method is as follows: Take a large bowl-not the one in which the salad will be served-and mix thoroughly half a teaspoonful of salt, half that quantity of pepper, and three tablespoonfuls of oil-adding the latter gradually. Slowly stir in one tablespoonful of vinegar - with or without a little tarragon vinegar. Place the well-dried cold asparagus, cut into half-inch lengths, in this mixture, and thoroughly shake it until it becomes uniformly saturated with the dressing. Lift it and place it in the salad-bowl, throwing away the liquid which remains in the mixing basin. It cannot be too often said that salads should always be mixed immediately before being served.

Mrs de Salis advises that the salad be sprinkled over with grated ham, or with tiny strips of smoked sausage, but these are, it is hoped, not additions which will appeal to many. 


\section{CULTURE OF SEAKALE}

\section{General Description}

SEAKale is a perennial in the truest sense of the word, for when once established it is very difficult to exterminate. Every little piece of root will form a plant, and being thus so hardy it in some cases becomes a nuisance in the garden. Reproduction can be effected either by division of the roots or by seeds; though I have always found the former process the more satisfactory, and this method is simple and easy.

In digging up a seakale plant to force, if it be properly removed, long white roots or thongs will appear, resembling thongs of leather. If you examine these roots, you will find those from seed more thonglike, and the older the plant from whence these roots spring the more woody are they. Again, if grown in a wet soil of a clayey nature, on cutting them a blackish mark or inky vein will be noticed. In seed plants, if young, this is not found; so for propagation I prefer such to plants raised from cuttings. I will give you my experience of seed raising first.

There is no doubt but that plants can be raised in two years from seeds. As with all other crops, we must start with a clean soil free from weeds. If this is to be a permanent site, we should select land where convolvulus, ground ivy, couch, and other persistent weeds are not, for it will be almost impossible to exterminate such when the plants are established. 64 
Sow the seed thinly in drills of fine earth, about an inch or more deep. The distance allowed for each plant will vary according to our plans for the future of the bed, but it will be safe to name eighteen inches; for, if the bed be made a permanent one, every other row can be cleared away later, and the plants left double the space

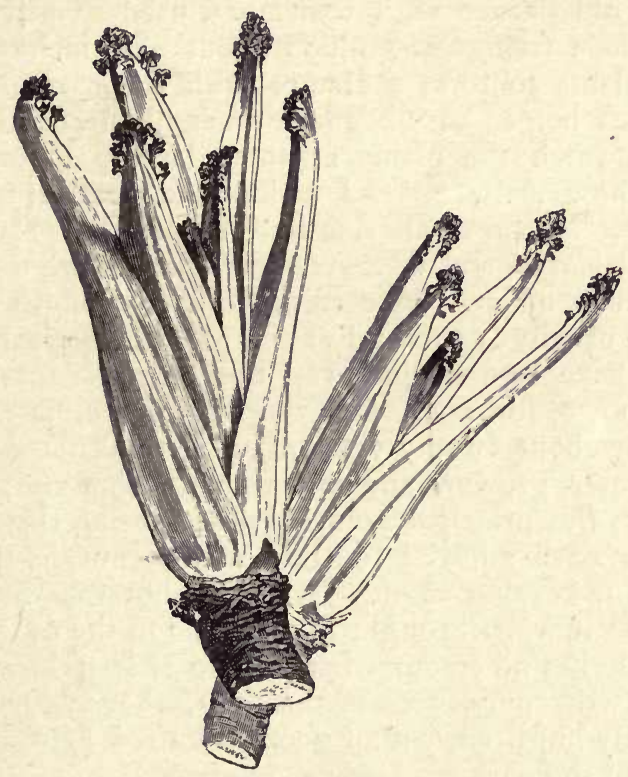

SEAKALE

apart if wanted to force under pots (a process now almost obsolete). Any plants not required can be taken up in the following autumn, and planted at a distance of one foot from one another, in rows eighteen inches apart. Break off any thongs from these young plants, so as the stem of the seedling plant is say six inches long. Cover up as many of these roots or thongs as are as 
large as a good-sized cedar pencil under soil of any kind. In times past I have planted seedlings closer than I recommend, and I have had reason to reproach myself for so doing, for the seakale makes such rapid growth, and produces such large stout leaves, that it is necessary to give ample room for development from the start.

The old gardeners, I remember, used to place their plants in a triangular position about nine inches apart, three plants to form a clump, with the natural result that each helped to "beggar its neighbour." One has but to watch the plants as they develop in order to realise how matters stood under that treatment. The crowding of the small side buds causes the production of small leaves, and wherever small leaves are there are weak buds under. According to the strength of the leaf, so usually is the bud at the axil of the leaf.

We have two distinct varieties of seakale: the old one, known for ages, and the lily white, introduced probably about twenty years ago. I think the old kind the stouter grower, and when well balanced perhaps the best, the principal point against it being that if the tips are once allowed to start with a purple tint, no forcing or keeping in the dark will obliterate it, which is against it when brought to table. On the other hand lily white has no colour whatever, so that if in starting the growth commences in the light, the colour is not materially impaired, yet all good-flavoured kale must be grown in the dark.

It would appear that these two maritime plants, asparagus and seakale, are not so easily persuaded to alter their primitive and unique identity as are so many other members of the vegetable kingdom. I cannot say if this be why they are not better understood. That they are so little understood and appreciated is more the fault of the people than the plants, for few plants respond to good treatment as do these. Seakale is so extremely 
hardy, and the means of propagating it are so simple, that there really is no reason why it should not be more generally grown.

\section{Propagation and Culture}

There are two ways of propagating it-one by seed, the other by root cuttings. As the seedlings make good material for root propagation, I will deal with them first.

March is a good time for sowing. As a good preparation of the land is necessary, I will assume that a piece of ground has been selected; the stronger and richer the soil the better will be the results. The soil having been manured well with dung early in the winter, well dug, and left in a rough state to pulverise, at any time in March the seed may be sown in drills about two inches deep. The distance from row to row will depend upon ultimate requirements ; if for permanent beds eighteen inches apart will be an excellent distance, for then every other row can be removed, and the permanent plants in the rows can be left about two feet apart. This is for ultimate forcing on the beds-a matter which will claim attention later on.

When these seedlings have made a few leaves they can be transplanted thickly in rows, say a foot apart, and nine inches from plant to plant, and so left till the autumn or winter. If these plants are not required for any other purpose they will make excellent material to furnish cuttings, which is the general plan selected for propagation, as I find that the younger the plants the better and healthier the roots appear to be for this purpose. Yet for permanent beds, where plenty of roots can be had, I never advocate seedlings, for really none can surpass a plant grown from a piece of healthy root on well prepared 
ground. For my own use I would prefer a piece of healthy root of the size and double the length of one's little finger to the best seedling ever grown for a per-

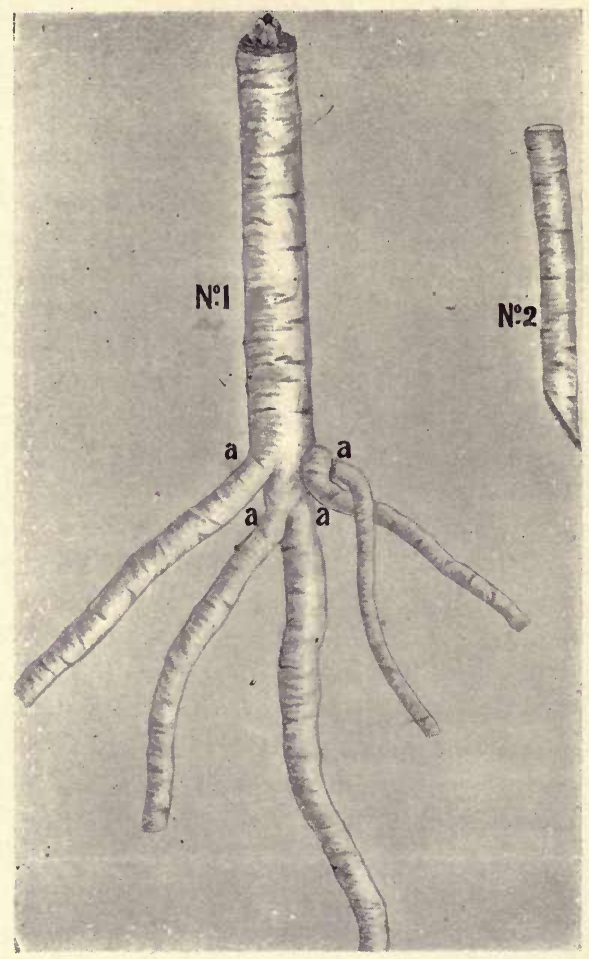

SEAKALE ROOT AND CUTTING

manent plantation. It matters little, however, whether the plants from which we take our cuttings be seedlings or plants taken up to force or sell. In either case well prepare the ground as for the seedlings, and cut off, or 
rather break off, the roots from the plant (see Fig. I), leaving only its trunk, the parts marked a. $a$. $a$. $a$. being the pieces for the fresh supply. Such are about five to six inches long, though pieces of even four inches make good plants. Cut the top level and the bottom in a slanting direction (see Fig. 2). This will guide the planter as to which end must be put in the ground, for I have often found a difficulty in distinguishing the top from the bottom.

Early in March, work the ground down, so that all clods are broken. If well pulverised by frosts so much the better, and the stiffer the land the better does it work down after frosts. The plants should be so grown during their first season that no older plants could be better for forcing in the following winter. The rows should be eighteen inches apart, and the sets twelve to fifteen inches apart in the rows on well manured and deeply dug land. Let a line be put down in order to have the rows straight. Put the cuttings in a shallow basket, take a short blunt dibbler, make a hole one inch deeper than the cutting is long, twist the dibbler round before it leaves the hole, so that the soil does not fill it up, and put the cutting in, so that it touches the bottom. A boy following a man can do this well, and it is far better and quicker work for two to do this than one, as there is no stopping to pick out the cutting, and if the earth crumbles, as probably it will, the cutting can follow the dibbler before the earth is allowed to fill up the hole. If the top be only half an inch under the surface it will suffice. After all is done a short-toothed rake can be put over the rows, and nothing more will be required than frequent use of the hoe to keep all weeds well under, and one small dressing of nitrate of soda, one pound to the square pole, with a dressing of salt as soon as the plants begin to grow freely. I am much inclined to discontinue salt, as is so usual, and apply before the 
planting time about five pounds of kainit per pole. There is a good deal of salt in this mineral, and it has the advantage over salt that it contains at least fourteen per cent. of potash. I have in many cases used the latter, as I am sure that the value of salt is over-estimated for many things. By salt I mean, of course, chloride of sodium. I have never yet found it as effectual as I was taught it is, and I do not care to hand down commentless an old tradition without proof of its efficacy. The proved value of seaweed has been brought forward as an instance of such, but one great use of this is its mulching quality, keeping the ground moist in very dry weather. The manurial value is very little compared with its bulk. Still I like it as a mulch, for it undoubtedly checks evaporation.

The finest seakale I ever saw was grown from such cuttings as I have described, planted in a stiff loam resting on brick clay, but the land had been treated in the following way. An old meadow was broken up and half trenched by taking out a trench two feet deep and two feet wide. The top soil was thrown in the first trench, and on it was placed a large quantity of dung; the under soil was broken a foot deep and left in its position, dung being put on the top of it followed by the top soil. Thus, the land was left as follows when finished-top soil on the top, dung between this and the broken subsoil. The land really was broken two feet deep, with dung sandwiched one foot from top and bottom. On this I grew in just a year from planting stems larger than an ordinary cucumber. I had probably one thousand plants, and I put over each crown in February old meat tins, six-inch flower pots with clay over the holes, in fact anything I could get, each covering being well screwed down into the soil to exclude light. I had several dozens of six-inch drain pipes, and for one-year-old crowns I would wish for nothing better. 
This bed looked a motley picture when I had used every available article to cover up my thousand plants. The reason that I did not cover any crowns with earth, sand, or ashes was that the soil was much too stiff to use, and ashes are objectionable, as they get into the base of the stems and are difficult to get out, whilst of sand I had none. Over all these makeshift appliances I put a good covering of strawy litter after filling up between with leaves. This was the opposite of forcing; it was retarding, and when the kale came on and was fit to cut, I do not remember ever seeing better, as but few weighed less than half a pound each, and many were a good deal heavier. The kale was about nine inches long and as white as possible.

Now, had I bought the best plants ever sent out, I should not have surpassed this bed and its results. I find many who, when they put in good strong plants, have them in flower in June when they are in a measure spoiled. I advise anyone planting such to put a six-inch flower pot over each crown, screw the pot into the earth or firmly on it, then put a piece of good clay over the hole, when each plant will produce a fairly good stem which can be cut with at least half an inch of the crown, though this will not be as large as that which I have above described. If this be not done, do not allow the plants to flower, but cut off the crowns early, and then others will be formed during the season.

I now come to the autumn when the bed of cuttings has done its work. Should a permanent plantation be required for out of doors forcing, every other row could be dug up together with every alternate plant in the rows which will be left, thus giving three feet from row to row, and two to two-and-a-half feet from plant to plant in the row. When these plants are taken.up, carefully remove all roots, for any pieces left in the ground will grow, and this is most undesirable. The 
plants taken up can be treated as follows : break off all roots close to the stems and put under some earth for cuttings. On a wet or frosty day when out of doors' work is at a standstill these can be cut out into lengths for next season's planting. The plants thus taken up can be forced, or if not wanted at the time of taking up, they, like the roots broken off, should be stored away in soil, packed closely together crown uppermost, so that when a quantity is required for forcing or sending away they are ready to hand.

\section{ForCING}

There are innumerable ways of forcing, in fact, so long as a dark place can be secured with a temperature of fifty to sixty degrees, all requirements will be met. The roots can be packed in light soil closely together, leaving just enough room for the kale to grow up, the crowns being just under or even level with the soil. On this I like to put a good covering of wheat straw or dry sweet leaves-but before doing this the plants should receive a gentle watering to settle the soil and to give the necessary moisture. Should the conditions be not dark enough, a frame should be fitted over so that the plants will be as in a box with the lid on. A very gentle heat is sufficient, at first fifty degrees being the maximum, rising to sixty-five which is the highest permissible if good stout kale is required. This should not be longer than eight to ten inches, for should it be allowed to grow longer, it would be well on the road to ruin. Such kale cooks badly, indeed, the shorter the kale the better does it cook-personally I prefer it to be about six inches in length. Cooks are often blamed for hard and tough kale when the fault is really that of the grower-who has left it too long before cutting. To 
maintain a proper supply, that is a continuous supply, a weekly batch according to demand must be started. In a general way, it is good practice when a quantity is cut to replace it by a new lot so that there need be no break in the supply.

Such places as mushroom houses, or under stages of intermediate houses, can be utilised, or indeed any places with the required temperature, but in large forcing establishments proper houses are devoted to this work. I will explain a few methods which I have adopted for utilising materials which would otherwise not be called into service for anything.

It was my fortune some years ago to have charge of very large plantations quite near an oak coppice. In the fall I had all the leaves collected into a large heap. This was levelled and well shaken up, a gentle and very lasting heat being thus secured. Some two light frames were placed in position and about four inches of rotten leaf mould put over the area of the frame. A quantity of seakale plants grown as described were then packed rather thickly in this frame and soil was banked up to the plants as they were placed in rows. When the frames were filled a gentle watering was given, the lights put on. Damaged hay was then put on the lights several inches thick, and a mat put over and fastened to keep all in place. I was careful to maintain a gentle heat which scarcely ever exceeded sixty degrees, and if it fell much below this a good banking of the neighbouring leaves, of which there were plenty, was made sometimes as high as the frame, so that the sashes only could be discerned. From a batch put in at the beginning of December I cut at Christmas, whilst from some put in later the time required was less, and from a batch put in in the first week of February I have cut grand stuff by the end of the third week of that month. I never tasted better seakale than this proved to be. It is no easy matter to 
force in this way when the days are shortening, but when they are lengthening it is a very different matter, indeed, one can reckon to the day when it will be fit to cut. These beds require but little water after the first is given, as evaporation is almost impossible, but should any be required tepid water is best.

I know an excellent grower of seakale who has not leaves in such abundance as I have just mentioned, yet has a limited quantity. He has made thatched hurdles of various lengths according to requirements. $\mathrm{He}$ has a trench about three feet deep and six feet wide in which he puts about two-thirds leaves and one of stable manure, which have been well mixed up and turned three times during the previous fortnight. When it is put in this trench the mixture is lightly trodden, and as the heat rises it is again trodden. When the temperature is somewhat going off he puts on a little light soil and places his plants in the same way as I have already described in speaking of my frames. When this is finished he puts on the thatched hurdles, thus forming a span roofed structure, and as he has only four feet of the bed under cover there is a margin of a foot on either side. On this he puts about a foot in thickness of the heating material, and, the ends having been carefully matted up, he puts in trial sticks to ascertain the heat of the bed. If more heat is required he adds still more leaves to the sides, and I shall never forget when one morning I paid him a visit. I found him uncovering the bed to cut. The produce was about six inches high, and stout, and this from one year's growth.

I have also used boxes, putting them in a cellar and filling them with a like mixture to that above described, keeping them perfectly dark, and I have had excellent results. I am sure that there are many such makeshift ways of growing good blanched kale other than that I have mentioned. I have often heard the 
old-fashioned plan of forcing in the open under seakale-pots ridiculed, but I venture to say that when properly done the quality is superior to that given by any other method of forcing. The best quality of forced kale is found when leaves alone are used, and if possible no other material should be employed. My plan is as follows, when plenty of oak, beech, or such kind of leaves can be procured (chestnut, lime and sycamore are too soft and soon rot and become useless): in the autumn, say about the first week in November, clear off the old leaves from the plants, slightly fork between them, fit on the pots and be sure the tops are perfect, so that the steam of the heating material does not enter the pots. Then, as the leaves are collected, pile up between the pots, shaking the leaves up so that the bulk is evenly distributed, for if left in irregular lumps the heat will not be satisfactory. When enough have been brought just to cover the pots, lightly but evenly tread them down around the pots, and then put another layer and tread in the same way. When this work is finished and the pots are well hidden, put a few sticks in the bed reaching nearly or quite to the bottom. In a week's time draw out these sticks, which when felt should be a little warm. If a few days later the sticks are found to be hotter, go over once more and tread the leaves more firmly. This will hinder the heat from increasing, and the more slowly the heat increases the better. If a heat of sixty degrees can be maintained after the first fortnight kale can be cut at Christmas. Of course in a private garden only a portion at intervals should be so treated. Sometimes, when the weather is very cold, a covering of long litter is put over all to keep in the heat, and this will be also useful to prevent the leaves being blown about. I am aware that even with the advantage which many people have of obtaining leaves, this method is laborious and expensive. It is very much 
cheaper to grow the plants annually as described, and to force by any of the several methods under glass.

When much out-of-doors forcing is carried on it will be necessary to remove the heating material after the kale is cut. Personally I never clear quite all away but leave a slight covering, as the change would otherwise be great in frosty weather, seeing that the plants have been treated to an unnatural temperature. When all is cut over and the weather warmer, in the early part of May, the beds should be slightly forked over and left. Shortly growth will commence and generally many more buds will start than it is desirable to have. As seakale has a large thick leaf, if too many shoots are left all the buds are in consequence weak or small. Now, the larger these crowns are the larger is the kale in the following year. So that here, as in every case where a crowd of leaves is allowed, small shoots follow. Therefore the plants should be gone over and all weakly growths (especially the under ones) cut out, two or three of the strongest alone being left. Otherwise, when the plants attain an age of several years, the shoots will vary according to the number of crowns.

I often see in old gardens very old plantations of seakale standing up in the winter like so many stems in a coppice, some a foot or more above the ground. If you examine such, you will find a good many crowns rotten where good ones should be. The reason of this excessive height is that when cutting, an inch or more of the old wood has not been cut, so that by degrees the plant has got higher and higher. The reason of the rotten crowns being where buds should be is that the plants have been allowed to flower, which is usual if plants be not well cut down. If these flowering stems are merely topped off, one of two things will followeither a mass of small buds on a sappy stem, or the death of the flowering shoot and the rotting of the 
crown alluded to. Many people are afraid of cutting low, but I have had plants even twelve years old quite level with the ground; when in the autumn the leaves are removed and the plants prepared for forcing, should there be late in the season a quantity of plants which cannot be forced in any way, they should, before growth commences, be covered up with coal ashes, sand, or light soil, over which should be placed straw or bracken fern, both being non-conductors of heat. This will prolong the season, as well as secure the kale from becoming purple, which a few hours' light (should the shoots break through) will effect, and one of the principal features in good kale is its whiteness.

There are many places by the sea where it grows naturally just above high water mark. The inhabitants between Calshot Castle and Leap in Hampshire, in the autumn when the shoots died down, used to put shingle a foot or more in depth over the crowns, the kale thus becoming beautifully blanched in the spring. The produce was taken to the Isle of Wight and Southampton. This practice no doubt is still carried on in the south of England, and there is no reason why such should not be any where carried out on the English coast where suitable and secure spots offer, and there are many such.

\section{Marketing}

When sent to the best markets, seakale is fastened to punnets and carefully protected by paper. I could never quite understand why punnets should be considered best. Would it not be better if kale were carefully wrapped in paper softly tied with raffia grass and packed like asparagus with soft material to prevent bruising ? Since being in the west of England I have found no good examples of growing or packing. In fact, where these 
operations should be carried out on a large scale they are most left alone. But there are indications that this will not long continue.

Any good shop or salesman will take kale when good, and there is always a ready retail sale for good specimens. 


\section{CULTURE OF CELERY}

Sowing THE SEed

Celery is a plant which has not become popular among all classes alike, and for this there is a substantial reason. for nowhere will edible celery grow unless it receives attention beyond that required by many other vegetables. It is a gross feeder and a gross drinker, and I never yet found land good enough to grow it without adding manure. It will in fact take any quantity in reason that may be offered it. I heard an old gardener once say the " wust of salary is that he's a glutton and a boozer," by which he meant that it requires high feeding all round.

Its wants are many, if it is to be developed to its highest state of perfection. The seedlings must not be drawn up by forcing, and crowding in the seed beds is a nuisance. Indeed, no check whatever should be allowed, especially through the lack of water. There is an almost universal opinion that celery is not really good till it has had a frost on it. I remember a gentleman who told me that he never touched celery till it had been exposed to frost. Now in that particular year there was no frost till the end of November, but plenty of rain, and better celery than was found then I do not remember. The secret is that celery requires a good deal of water, and the portion which is blanched in the dull days of autumn when there is a good deal of rain is of course better than when grown and brought to table in the months of September, October, and the first half of 
November. One certain thing is that the portion generally eaten is usually below the reach of an ordinary frost, and, when it is not so, much well blanched celery is found rotten after a severe winter. Celery is not altogether a hardy plant when blanched, though it is so

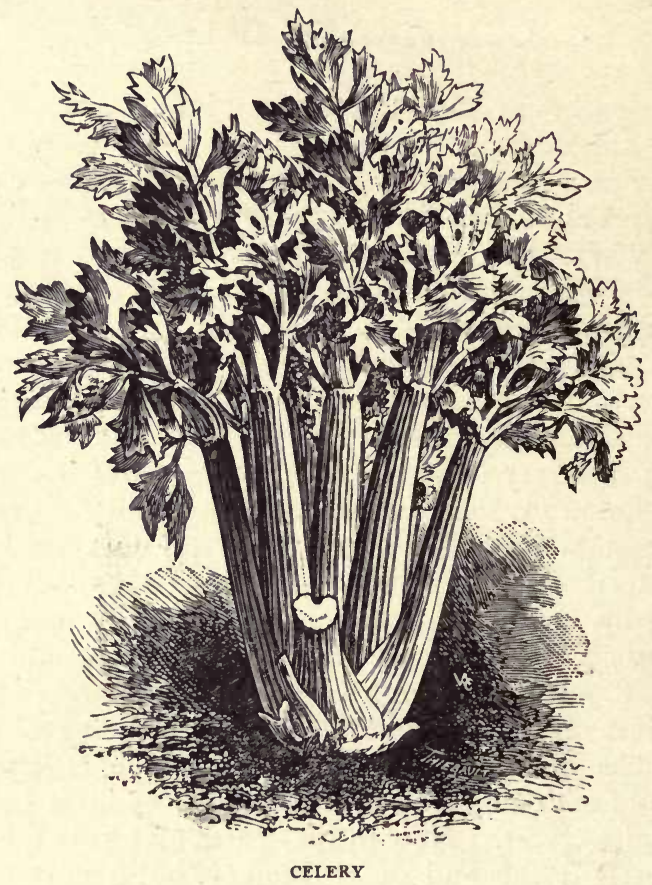

if not earthed up, but such is of no use except for flavouring soups.

To grow celery, light soil is not the best, and, unless plenty of manure and water can be given, the crop grown on such will be unsatisfactory. I prefer a medium soil, not too light or too heavy, but if it be the latter a winter 
fallow must be the means of bringing it into good working condition.

Seed Sowing.-Ilike to make three sowings - in February, March and April. The March sowing will be the principal, but where very early celery is required a pan had better be sown in February. A light, rich soil made rather firm is best for this. Generally about three times too many plants come up in a given space, crowding each other in their infancy, so sow thinly, cover up with about one quarter inch of fine soil, and then water gently. I place slates over the top of the seed boxes or pans, in order to prevent evaporation as the seeds germinate slowly. I give a brisk heat of 70 to $75 \mathrm{deg}$. till the seeds begin to germinate, when I remove the slates and put on glass to admit more light. A high temperature will be fatal to the future career, as nothing short of good sturdy plants should be aimed at. The slate and glass are not necessary if seed pans are placed in the shade. When the plants have made a pair of rough leaves they should be pricked out into boxes, seed pans, or even into frames ; if the latter, heat must be afforded for a time if for early work. The soil into which they are pricked should be rich with plenty of well-rotted dung, and if a sprinkling of bonemeal be added so much the better. The soil into which celery is pricked out should be rich and firm, especially that used in the final transplanting before removing to the trenches; if some well-rotted manure be placed under the young plants and made firm, then about three inches of good soil also made firm, and the plants put about three inches apart, these can be taken up with good balls of roots, which poor loose soil will never allow. This prevents the plants from flagging, and, when finally planted, they will start without a check, which is a most important matter. Many plants will not in the least be injured by a check when planted, but this is not so in the case of celery. We 
shall thus have plants in four different stages which will suffice from the earliest to the latest season.

Some large market gardeners sow broadcast in a frame on rich soil made firm, the soil being not more than six inches from the glass. This is for the general crop when a large quantity is required.

It will be well here to speak of varieties, of which there are many, and of which nearly every grower has his fancy. There are two distinct types, white and red, the white being the earlier. For many years I grew Sandringham White, a good sturdy kind, but in after years I grew Sutton's White Gem, a very early and partly self-blanching variety, and also their Solid White and Veitch's Superb White, and I prefer these to my old friend Sandringham. Major Clark's Solid Red and Fulham Prize are my favourite reds, and these will furnish any grower with all he requires, unless he wants exceedingly long celery (which I do not advise), and then he must look out for a "novelty," which perhaps will be coarse. I need not here remark that, as celery is an important crop requiring a good deal of care and labour, a few extra pence in buying the seed should not be considered, for, after all the time and labour has been bestowed, it will be worse than disappointment to find that one has not a good strain. I have had a whole planting of the three varieties named, and not distinguished a spurious one in the whole lot. This is what should be, and is what I have generally had in all my seed crops.

Every grower will be guided by his requirements as to how many plants should be grown, but, whether it be 50 or 50,000 , it pays to give the plants our best attention. I will here give an outline of my practice with the March sown plants, as this is the principal crop. The seeds are sown thinly in boxes, and when all are well up, the boxes are removed to a light airy 
place, where just a little heat is afforded. Soon afterwards they are transferred to cold frames and kept gradually moving till about the end of the first week of May, when on a well manured warm border made firm the plants are pricked out about two-and-a-half to three inches apart. When planted they are well sprinkled with water, and a few green rods are spanned over them, and also a few rods lengthways at right angles to these, a shading of thin material being placed over this framework to prevent flagging. At night a thicker covering is substituted, and the lighter shading replaced each morning for several days. The plants are then exposed to the sun all day, but covered up at night for a week longer if cold. In fact, as these rods are left on I cover them up occasionally till the 2oth of May, when frosty nights are anticipated. I sometimes put them in cold frames if I have them to spare. In any case these plants by the middle of June are ideal ones for planting out.

\section{Planting and General Treatment}

Very few people can afford to put apart a large piece of ground for celery plantations in the spring, neither is it necessary, as a crop of many things can be taken off before celery need be planted. Celery can follow the Brussels sprouts and other winter greens, or the first lot of spring cabbage which was planted in the autumn, or late broccoli, or even early potatoes.

There are several ways of planting-in single or double rows, or in beds; and although many people will not hear of beds, I can only say that there is more to be urged in favour of beds than many give credit for. I mean by beds four rows altogether, the plants a foot apart in the row, and about fifteen inches from row to row, The advantages are threefold - - less ground is 
occupied, when properly earthed up the rain does not run off, and in hard weather dry leaves can be packed between all the plants even to the tops. A covering of mats can also be used if a support of some kind be placed over the bed. I have formed a span covering of rods, banking with dry ferns and litter. In some parts of England the frost will go through the ordinary single or double row, and I have on many occasions found a good deal of the crop rotten when the frost has gone. I do not say that very large celery can be grown in this way, but it is a plan worth adopting for late celery; of course a bed of five feet wide must be made, the soil being thrown out about eight inches deep and plenty of manure being dug in. The single row, however, is the general plan, and good, well-rotted manure in abundance will be required in its making.

Of Manures.- The kind which I prefer is a mixture of pigstye and farmyard dung, especially if there be a good proportion of horse droppings with it. Rank, strong manure cannot well be dug into the trenches, neither would it be well for the plants. Therefore spread out the manure, and over each cartload put about three pounds of salt, and a peck of soot with half a peck of lime. Then turn over well, mix, and form a heap. This should be done in the early spring or winter. The mixture when well rotted can be thrown open, and left so that if worms are in it birds may visit the heap. I have often mixed this in the winter, and in hard frosty weather thrown it open, when the birds have worked about it and cleared it of worms, which are most injurious. Indeed many a good lot has been disfigured by worms, and they should be guarded against in every way. This will be touched on again later.

In digging out the trenches much will depend on the nature of the soil, also on its previous treatment. I have sometimes had to deal with stiff clay land, with 
only nine or ten inches of good loam, and sometimes less. It is not well to trench such land as this, or much of the clay is brought to the surface. I like rather to break up such subsoil, and leave it where found with a good layer of dung on it, pulling the top soil on the top of it. For celery trenches on such soil I take out the top spit and place it at one side of the trench; a small portion of the next spit is then thrown out and placed on the opposite side, after which a good deal of the top soil is put back to plant in, incorporating three or four inches of the manure. These trenches are sixteen inches wide, and when dug ready for the planting they are about four inches deep. I often see trenches ten inches deep, but no one can give the reason for such a depth. Sometimes my trenches after receiving the dung are nearly level with the ground surface. I never allow less than four feet from row to row, or, if double rows, five feet. I am aware that less space can be given, but much depends on the depth of soil and what is its nature. It would be really bad form to earth up at the last with a clayey soil, and one would have to do this in some cases where the rows are too near together.

There is generally at the time of celery planting a good deal of other work to which the gardener has to attend; in fact, it really comes at his busiest season. Hence it is that drawn-up plants are so much in evidence. Now, if plenty of room be given to the young plants in the nursery beds, they will bear a little delay, but I like to get the principal lot out by the end of June. They will bear no stint of water at any time. The distance which I give from plant to plant of Sutton's Gem is nine or ten inches, but with the later and stronger growers I allow a foot apart. Every plant is taken up carefully the day before planting, and I well water the plants to soaking point. A spade is put under the plants as in taking up a thick turf, a man taking up each plant 
and putting it in a flat or flattish basket or on a handbarrow, on which the plants are taken to the planters, who with trowels draw the soil forward to make the hole. Each plant with all its roots is placed well in, and a man or boy following with the water-pot gently waters.

I like to plant as soon as a trench is ready, so that if it be sunny weather the soil does not become dry before planting. This may seem a small matter to some, but no one can plant anything properly in dusty soil. I have seen it advised that the plants be shaded with boughs. This is probably necessary when drawn-up plants are planted, for long watery leaves will flag, and when such go down they remain down for a considerable time if the weather is hot. Such plants simply are a reproach to the owner-I would say grower, were it not absurd. I have also seen plants cropped off, I mean the leaves cut off, so that they should not flag. I need not comment on this. The reason for this again is that two plants had been grown where room was for one only. This vice of overcrowding is one of the greatest in horticulture.

Should the weather be dry, water must be given, but not necessarily often. Whenever it is given, immediately cover up the watered soil with an inch or a little more of the dry soil; this will prevent the sun from raising it and save much labour. The dry earth will shut in the moisture; this hint applies to other plants as well. I have known many people carry the water-pots a long distance to water plants every night, whereas if one good soaking were given, and a little earth drawn up around the plant in order to prevent the sun drying up the water the next day, much labour would be saved. If when watering takes place an application of manure water be given occasionally, so much the better. If used too strong, however, this will encourage spongy and coarse growth, 
and so spoil the quality. Some growers make this mistake of over-feeding when size alone is aimed at, but the quality is spoiled thereby, for although celery will take a good deal of manure, discretion must be used. I have often seen this mistake made by amateurs who grow for exhibition, and think that all depends on the quantity of manure used. When the celery is brought to the exhibition table and cut through, a coarse spongy growth is all that remains. It must be understood, however, that I advocate generous treatment, but the difference between this and over-feeding is much the same as in rearing pork.

Eartbing up.-This must always be done on dry days, but previous to the first real earthing a thorough watering should be given, in fact a soaking if possible. A sprinkling of soot if available should follow, in order to prevent worms crawling up the plants. On the next day the earthing can be done. The plants must be examined and all suckers removed. I am assuming that the plants are very far advanced in growth, and that the several little lots of earth have been applied after each watering, so that the trenches will be level or nearly level with the surrounding soil.

On the morning of earthing, break down sufficient soil, and make fairly fine, so that all will be ready when the earthing up is done. Two people at least should perform this operation, and if three can be spared so much the better. Many people tie up the plants with matting, and some put a paper band around them before earthing. I need not say that where a large quantity is grown for market or otherwise such is impracticable. Moreover, if the work be properly done, it is not necessary. The leaves should be gathered up and the soil carefully packed between the plants, not a particle being allowed to enter the heart, or even between the stalks. Do not bank up too high, but keep the hearts well above 
the earthings up at all times. As we have a thirsty plant to deal with, this first earthing must not as in so many cases be high. I consider three earthings sufficient, the last not to be done till the end of October for the general or winter crop. Even then see that the earth does not get to the hearts, for many people, thinking to exclude frost, will recklessly cover the plants, so that the whole is nearly hidden under the soil. Should sharp weather occur, bracken fern is the best of all things to use, and earth on the top the worst.

I will now deal with the exhibition lot. The same work will have to be done here as for the general crop; but the plants, having been prepared earlier, will of course be put out earlier, and a little extra care bestowed. The plants must have a little extra room, about fourteen inches from plant to plant being a good allowance. See that no worms are in the manure used, and of this an extra inch or so may be dug in rather deeply, because as all growth will have to be made in hot weather it will be well to encourage the roots to go down in search of food. The plants, being well preprepared, should by the middle of May be planted in these well-prepared trenches, which might also be a little deeper, say by two inches, than for the general crop. See that no suckers spring up, and remove early any which may appear. Each watering must be thorough, drawing over the surface the dry earth as before advised. Weak guano water can be used with excellent results. Place in a barrel or tub holding say thirty-six gallons, two pounds of guano, a gallon of soot, and a little lime, fill up with water, and stir. If the soot be put in a coarse bag and kept under, it will be much better than putting it in loose. In the space of a fortnight this mixture will be ready to use, and onethird of this to two of clean water will be strong enough. This might be used once a fortnight, a water- 
ing of clear water should the weather be dry being given between, so that the total waterings will be given once a week. Should this be done properly, and no check have been previously suffered, these early plants will grow freely and not run up to flower stems, as so frequently happens to all early-raised biennials.

For these exhibition plants I advocate paper bands or celery collars, but not till the plants are well grown and the first good earthing given. The soil for this lot, if it can be obtained, should be of a light sandy nature, for the more it borders on clay the more undesirable it is. Cut slips of brown paper, and lightly bandaging with them not too high up, tie loosely with matting or raffia grass. Then carefully earth up to the height of the paper, pressing the soil firmly around each plant. In three weeks from the first the second earthing can be given, and this time another strip of paper and raffia grass applied, so as just to hold the leaves together. With a rather bluntlypointed old rake, hoe, or broom handle make holes diagonally a few inches deep near the base of the trench, and into these holes pour some water, but be sure not to water over the tops of the plants. After this trenchwatering throw some earth over it, and bank it to the sides where the holes were made. If this is done well no other watering will be needed. When the plants are well blanched, which will be about a month after the last earthing, they may be dug up as required, though even this requires great care. Remove the soil well away at one end, and carefully with a spade (not a fork) raise each plant. Take the plants to the shed, or somewhere where they can be kept from the sun, and till the morning of the show do not remove a leaf or outer stalk, and the roots must not be over-trimmed till then. Should it be necessary to wash the celery, though I think it best never to do so when thus grown, carefully remove just an outside stalk or so, then with a soft 
brush and a pail of clean water, holding the plant upside down, gently wash it. Then dip the top in another pail of clean water, to wash off what dirt has rinsed down, afterwards laying it carefully on a clean bench. Celery should be judged by cutting down the middle, so that the quality can be discerned, though if three or even two sticks are shown, one only of each exhibit need be cut. Do not over-trim either for exhibition or market. In the matter of roots or plants of any kind, I always prefer the soil left on rather than washed off. Vegetables always keep fresh for a longer time when not previously washed. Of course, for exhibition the appearance of the washed roots is preferred.

Very late celery is sometimes required, especially for soups, for which it is indispensable. This, if sown outof-doors in April and planted out at the end of July, will require but little earthing. It is then invariably quite hardy, and can be planted about three feet apart in trenches not necessarily as rich as those already described. Cooks require celery all the year round for soups, and when in the spring, by the middle of April, it is found growing up, it can be lifted and packed under a north wall or in a cool open shed, soil being well packed around it. This will carry the gardener on till he can afford to supply young strong plants for flavouring. Cooks never cease to ask for celery, and will not hear of anything they require being " out of season."

\section{Insect Pests}

Celery is sometimes visited by a most destructive insect called Tephrites Onopordinis, which visits the plants when very young, and does a great deal of mischief. The eggs are deposited on the leaf, and the larva finds its way into the leaf's substance, and thus secretes itself, 
so that no outward application can reach it. The blister-like blotches which result may be pinched off and burnt or thrown to the pigs. But the only real remedy that $\mathrm{I}$ know is to sprinkle or dust with very fine dry soot and lime, two of the former to one of lime, once a week at least, early in the morning, when the dew is on the leaf. This, which is to be applied when the plants are first pricked out, will make them obnoxious to the insect, for I am much inclined to think that it is enticed somewhat by the odour of the plant, as happens in the case of parsnips and parsley, which are not unlike in this respect. Even when the celery is finally planted out, the same dusting once a week till the middle of July will be beneficial if done lightly.

The slug is another enemy, especially to the young plants, so that in raising or planting out always avoid proximity to a spot which harbours them, such as boxedging or hedges of any kind. 


\section{- CULTURE OF CELERIAC}

Of celeriac, commonly called turnip-rooted celery, there are several varieties, such as the Smooth Paris Celeriac, Early Erfurt, a rather small kind, and Prague Celeriac, the latter being a larger variety of the smooth Paris, but the varieties or variety which any good seedsmen sell will generally suffice.

Here it is the root only which is used. I consider it strange that a vegetable of this class is so little known, especially as in the winter vegetables are not too numerous; yet it is easily grown if sown and treated as other kinds of celery, and afterwards planted out in rich soil.

March is the proper time to sow, and a box a foot long and nine inches wide will raise a thousand plants. Prick out and treat as instructed for March-sown celery, then, on well prepared and heavily manured ground, plant in rows eighteen inches by fifteen, the ground having been previously made firm, for it is, like most other bulbous plants, at home in firm soil. Some growers give even more room, say two feet by oneand-a-half feet. Celeriac will thrive best on soil not too stiff, in fact, a soil of a sandy nature firmly made is best, as the bulbs are always finest when standing, like onions, well out of the ground. No earthing up will be required; in fact this would in a measure spoil the plants. Frequent hoeing is necessary, and one must be careful that the soil is not drawn to the bulbs but kept clear away. When any shoots or laterals form they may be 
removed, though I am not clear as to any great advantage being gained thereby, yet if I detect them when planting out they are removed. If planted very shallow, the hoe being frequently used, a good crop is generally procured. If the summer is very dry, a good soaking of water will be beneficial, as celeriac, like celery, delights in moisture. The roots when liberally grown are of

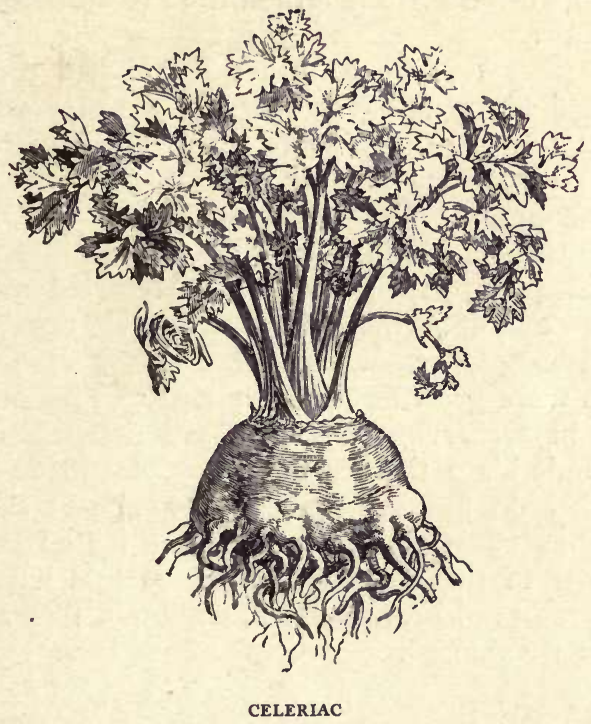

finer quality than when stunted by being grown under unfavourable conditions.

When fully grown, before winter or frost sets in, it is well to take up a large quantity of roots and store them, as is done with beetroots. They are not really hardy, but in mild winters they can be left in the ground till February, especially if soil be drawn over the roots. Still, like all biennials such as turnips, parsnips, beet, 
etc., when fresh growths commence in the spring, a deterioration will certainly ensue, if the roots be left in the ground; so they must not be left too long, but be packed away in a very cool place in sand or sandy soil. 'Some people recommend coal ashes, but I do not use them for roots of any kind. Dry leaf mould I prefer to ashes, but sand is best of all. The secret of keeping such things in order to lengthen the season is to exclude heat and air.

I remember that once by accident I had a cart-load of white field turnips put down in a heap early in the winter. The next day some excavations were made, and for convenience several tons of soil were thrown on the turnips. I discovered this when too late, so I had more turnips brought from the field to replace them. In the following April this soil was carted away, and when we came upon the buried turnips they were fresh, firm, and as good as when carted there, whereas all in the fields were grown out and spongy. This taught me a lesson in preserving roots. I saw that when the air was excluded not the least growth was made by roots or tops. I do not say that so large bulks should be always thus covered, yet such might be advisable for all I know to the contrary. Since then I have in like manner preserved beet, celeriac, and such like roots till new ones are wanted. 


\section{CULTURE OF SALSIFY}

SALSIFy or vegetable oyster is a vegetable which ought to be more grown, and even where it is cultivated should generally be better grown. All soils do not suit it alike; in fact, to grow it well is not always an easy matter, for so much depends on the ground available. A deep sandy rich soil is best. To manure stiff soil and expect good straight roots will end in failure. If the soil be poor, do not mix dung with it, or the roots will branch in all directions and will become useless. Rather put the dung ten inches deep, so that when the roots reach as far they can be fed by it. I prefer using a slight sprinkling of guano and super-phosphate well worked in previous to sowing. Sow on well dug ground made fairly firm as for parsnips, and draw drills about the same depththat is, one to two inches-the drills being a foot or fifteen inches apart. When the plants are up, thin to five or six inches apart, hoe well, and keep clean. Nothing more will be necessary in order to obtain good roots, straight and without rootlets.

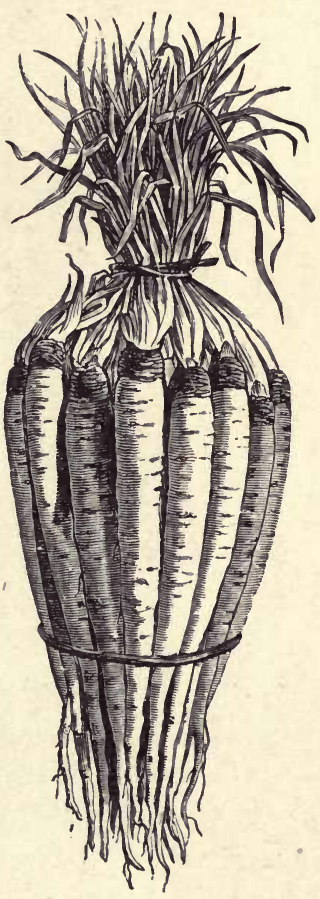

BUNDLE OF SALSIFY

Only a few weeks ago I was in a garden where was a large bed of salsify. The owner was not satisfied with 
96

\section{CULTURE OF SALSIFY}

the plants, and told me that he had changed his seedsman, because his salsify was so poor and straggling.

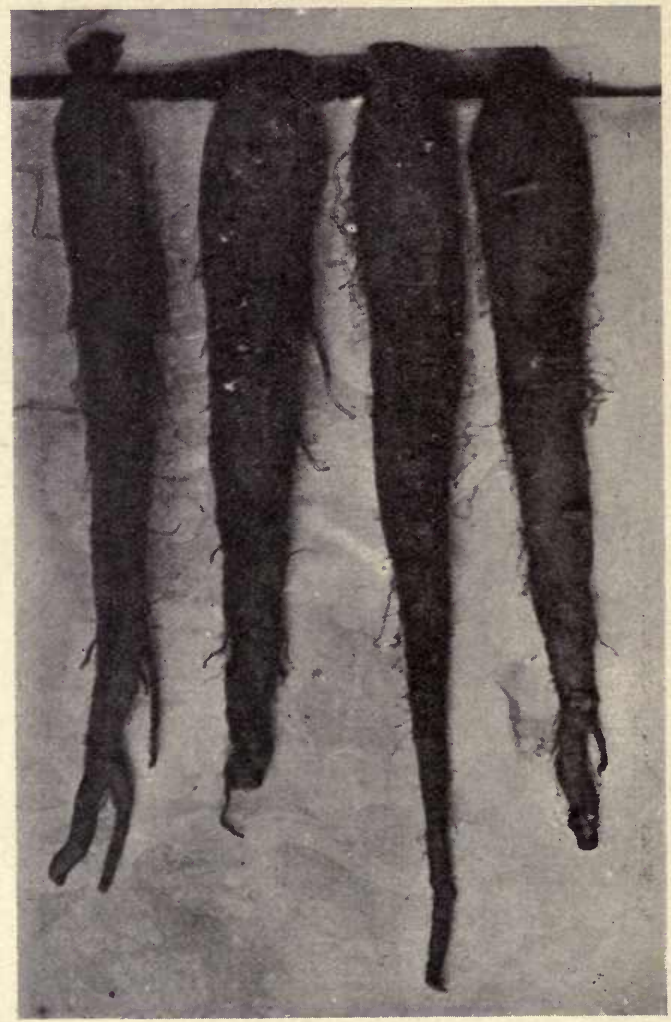

SALSIFY ROOTS

I examined the bed, and counted eight plants to the foot run. I turned to the other side of the bed where broccoli was planted, and found them about a foot apart from 
row to row and less in the rows. They were about three feet high, so I said, "Your broccoli is also a failure." "Yes," he said ; "no more seed from Messrs Soand-So." I said, "Are you not blaming your seedsman for your own ignorance?" He said, "Well, my gardener is of the same opinion as myself." I asked to see the gardener. He replied that he had not one now, but wanted one. I replied, "Yes, you certainly do want one, as it seems to me you have not had one lately." I then told him what I thought, and wondered how often our nurserymen and seedsmen are blamed for our incompetency.

I consider that salsify cooks better when raised from the ground as required, in the same way as parsnips. But when growths commence the roots should be taken up and stored away, for new growths mean pithy and tough substance which will neither cook well nor look well when served up. 


\section{CULTURE OF SCORZONERA}

Scorzonera is a native of Spain, and is probably less

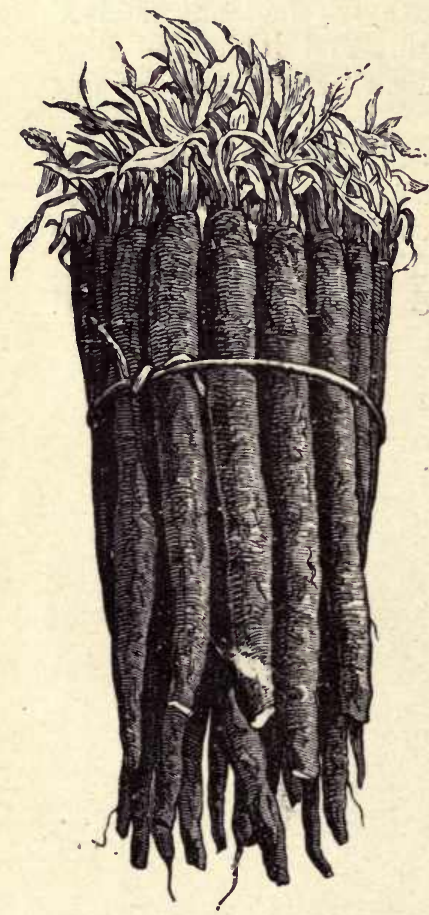
known than any other vegetable dealt with in this book. It is much like salsify, the roots being the part eaten, differing in appearance from salsify, however, in being somewhat darker. It is a perennial, but it is scarcely ever used as such, being treated as an annual or biennial much as carrots and parsnips are treated. There is, however, a variety which is an annual, Scorzonera picroides. This is a native of the south of Europe.

The culture of scorzonera is identical with salsify, but bispanica being a perennial can remain in the ground over the year without losing its quality by so doing, though the size of the roots increases.

BUNDLE OF SCORZONERA 


\section{HISTORIC AND CULINARY}

"Chou marin sauvage d'Angleterre," was the term used by Valmount de Boman to describe the seakale, and it is a curious fact that though this delicious vegetable has been for so long cultivated in England it has never succeeded in establishing a real footing across the Channel, in spite of numerous attempts to introduce it from the time of L'Obel, about I8Io, onwards. One may search the pages of the French cookery books, even the book of Gouffé himself, in vain for any reference to this delightful vegetable. Yet, when properly grown and properly cooked, it perforce appeals to the most fastidious palatè, so that when a French cook such as Ude settles in England before compiling his text-book, he too falls under the spell and is bound to recognise the plant's virtue.

It is a native of England, and long before it was cultivated in gardens was known and appreciated by the natives of those parts of our coast where it grows. They cut off the young shoots as much as possible below the surface of the ground, thus obtaining the flavour peculiar to the blanched condition. In the large two volume work in folio entitled "A Complete Body of Planting and Gardening," by the Rev. William Hanbury, published in 1770 , a short section is devoted to the plant. "The Sea Colewort," he says, "is now preferred by many as an esculent to most of the spring productions. It has not been many years introduced into the garden for kitchen use, but has been long known to the inhabitants who live near the sea, where the plant grows naturally, and who gather it in the spring as soon 
as ever, or before, it comes up; which they know by the rising of the sand which the shoots occasion, as they are ready to appear; and being cut so early even within the ground, they are of a more delicate sweetness, which they lose by degrees, and become tough after they have been exposed to the open air."

It was stated in "Notes and Queries" that seakale was first sent to the London market about 1710 by the Rev. John Freman, vicar of Sidbury; but that the vegetable failed to take hold is obvious from Curtis's statement a hundred years later, "that attempts had been made at various times to introduce seakale into the London markets, but ineffectually." From the time of Curtis onwards, however, seakale has steadily grown in popularity in England. In France it is even yet but little grown, though more so than when Ude wrote in his "French Cook" that "this plant is not known in France."

In America also it is not so well known as one would expect, and we may examine many of the standard American books on cookery without finding its name. Seakale, although with an utterly dissimilar flavour, may be cooked much in the same way as asparagus. Only just so much of the main stump should be left as will suffice to hold neat little bundles together. These should be placed into boiling salted water and boiled for about twenty to thirty minutes until the fork test proves their tenderness. The seakale should then be served on dry toast, a vegetable-dish with drainer, or a napkin, as recommended for asparagus. Any of the sauces, moreover, named as suitable to be served with asparagus are equally suitable to be served with seakale-in either case, of course, in a sauce-boat and not poured over the vegetable. As is the case with asparagus, it is as a plain vegetable with or without sauce, that seakale really shines; but there are many other ways in which 
it may appear on the table without breach of artistic decency. It may indeed be used instead of asparagus in any of the recipes previously given.

\section{Seakale au Jus}

consists of seakale boiled as directed for fifteen minutes only, then put into a stewpan with a sufficiency of gravy to cover it, and stewed till tender. Place the seakale on a dish, thicken and Alavour the gravy with a little flour, butter, pepper, salt, and lemon or tarragon vinegar, pour it over the vegetable and serve.

Those who like that sort of thing may enjoy

\section{Seakale in Cream,}

that is seakale boiled as directed, and served covered with white sauce, into which a small cupful of cream has been stirred at the last.

To make

\section{Seakale Soup,}

take a dozen heads of white seakale, cut into inch engths, and place with two ounces of butter in an enamelled pan. Heat carefully for a few minutes, shaking the while. Then add a sliced potato, a sliced onion, a teaspoonful of salt, a little pepper, a little grated nutmeg, a pint of water, and half a pint of milk. Boil for an hour. Then rub the whole through a wire sieve, boil up again, add two tablespoonfuls of cream, and serve with toast.

As a salad, cold boiled seakale should be treated in the same way as advised for asparagus.

Scorzonera is one of those vegetables which were once more frequently grown in our gardens than is the case at the present day. The plant grows abundantly 
in the wild state in Spain and less frequently in the south of Germany and France. It first attained notoriety on account of its alleged virtue as an antidote to snake's bite-hence the popular interpretation of its etymology -the word being thought to be derived from escorso, a snake-the fact of course being that it owes its name to the colour of its root. It seems to have been introduced into England about the end of the sixteenth century, though it was probably cultivated at first more for its supposed medicinal properties than as a pleasant addition to the table.

About the beginning of the seventeenth century it was evidently known as a delicious edible, and is referred to in "Le Jardinier François," published in I6I6. From the middle of the seventeenth century onwards, recipes for its cooking are to be found in most of the better French, American, and English cookery books, though in France it has never been a popular vegetable in the sense that the more delicate salsify is popular.

In Hay's translation of Lemery's " Treatise of Foods," to which reference has been already made, both these plants are classed together as "saxifrage," of which the author says: "There are two Sorts used for Food; the first is a Root of a Kind of Goat's-beard, and the other of Scorsonnere, commonly called the Saxifrage of Spain." The latter, he says, has "a more agreeable Taste than the other, probably because it is endu'd with some more volatile and exalted Principles."

Salsify, like scorzonera, is much less grown in England than was once the case. Evelyn refers to the common yellow goat's-beard as "an excellent salet root," and Parkinson also mentions it as a cultivated vegetable. The salsify, or purple goat's-beard, also occurs wild in England, but it is certain that such plants are merely escapes from gardens. Both species close their 
flowers early and have thus earned the nickname, "Johngo-to-bed-at-noon." Johns, in his "Flowers of the Field" (I 889 edition), says that salsify "was formerly much cultivated for the sake of its fleshy tapering roots, which were boiled or stewed and eaten. Its place is now supplied by Scorzonera Hispanica; but directions for its culture are still given in most gardeners' calendars."

Salsify and scorzonera are cooked one much as the other. The latter, however, should not be scraped before being boiled, but should be peeled after being cooked. To boil salsify, a dozen roots should be first well washed and scraped and at once put into a basin of cold water with an egg-cupful of vinegar in it. In five minutes place the roots in an enamelled stewpan containing a boiling mixture of half a pint of water, quarter of a pint of milk, two slices of lemon, a little salt and half an ounce of butter. Boil until quite tender, which will usually be in about an hour's time or a little more. Take out the salsify and well drain it. It may be served whole, melted butter, beurre fondu, or sauce Hollandaise accompanying it in a sauce-boat. Or the boiled roots may be cut into inch lengths, and a layer of them placed at the bottom of a fireproof pan, seasoned with pepper and salt, and covered with a little bechamel sauce, this arrangement of layers being repeated till the pan is full. Over all sprinkle grated Cheshire, Cheddar or Parmesan, and having covered it with very small pieces of butter, heat for a few minutes in the oven.

\section{Salsify in Scallop Shells}

Boil as directed, then mash and warm the boiled roots in a pan with a little cream and lemon juice, shaking the while. Fill scallop shells with this, sprinkle with bread crumbs and a little grated cheese, and, having heated in the oven for a few minutes, serve. If liked, 
a teaspoonful of anchovy sauce may be added to the mixture before putting it in the scallop shells.

\section{Salsify and Eggs}

Boil, mash and then season a dozen roots with an ounce of butter and a little salt and pepper. Into a cup of cream incorporate a cup of bread crumbs and a wellbeaten egg. Mix this with the salsify and, having covered with small pieces of butter, bake in the oven. Serve with a cut lemon. Instead of being baked, the mixture may be made into little cakes, dredged with flour, and fried.

Hanbury, in the book previously referred to, says : "There are various ways of dressing the roots of Salsify, though the most common method is to boil them first, and then slice and fry them with flour and water." The proper way to fry them-and it is perhaps the best method of cooking them-is as follows :-Boil the salsify as directed and cut into inch lengths, which dip in the following batter and fry a nice brown. Mrs Roundell advises that grated cheese be dusted over the fried slices. The batter may be made by thoroughly mixing into a paste quarter of a pint of water, quarter of a pound of flour, half a saltspoonful of salt, two tablespoonfuls of salad oil and the yolks of two eggs, adding the thoroughly-beaten whites of two eggs.

In all the above recipes scorzonera may be used instead of salsify. Salsify and scorzonera may be wisely used to make soups much in the way advised for seakale. The cold boiled roots also make very pleasant salads. Boil the roots as directed, dry, cut them into inch lengths, allow them to become cold, and then pour over them oil, vinegar, a little tarragon vinegar, pepper and salt, and thoroughly shake as previously directed for making asparagus salad. Any of these cooked vegetables may be served in aspic if desired. 


\section{Celery}

Celery is a native plant occurring wild in moist places, usually by the sea. It has long been known in its wild state, and is referred to by Homer. Pliny described a cultivated variety, and ever since that time the gardeners of most European countries have devoted considerable skill and attention to the culture of celery and to the raising of new varieties. It is included in the list of vegetables named in the report of the survey of the monastery of St Gall made in the year 873, and nearly every English work on gardening gives directions for the proper growing and blanching of the plant.

Celery is known and used in England chiefly in a raw state, as an accompaniment to cheese, and certainly that is one of the most useful and pleasant ways of eating it. For this purpose take some heads of fresh blanched celery, cut off the green parts and the outside leaves, and also remove the stalk ends, wash in cold water, and serve in a celery glass. Or the raw celery may be cut into thin slices, the delicate leaflets being reserved as a decoration for the top, and placed in a salad bowleither alone or mixed with slices of cold cooked beetroot, or with split filberts or walnuts, - a salad dressing, as advised for asparagus salad, being poured over the celery immediately before serving. Do not shake this salad, or the crispness of the celery will be lost. It may be garnished with celery tops, cress, or lettuce leaves. To

\section{Boil Celery,}

take six or eight heads of fresh celery, remove the outside leaves and the green parts, and neatly trim the main stalk. Cut to a uniform length of about six inches, well wash in cold water, tie in neat little bundles, plunge them into a saucepan of boiling salted water, and boil until tender. Serve as advised for seakale. 


\section{Celery au Jus}

is prepared in a similar way, but the celery is removed from the boiling water at the end of ten minutes and carefully drained. It is then placed in a stewpan with a little fat or oil (quarter of a pint to six heads of celery), tossed over the fire for a few minutes, when are to be added a pint to a pint-and-half of stock, sweet herbs, a carrot, a tomato, a small onion, and a little pepper and salt. Stew for an hour and a half. Place the celery neatly on a dish, and having strained the sauce (thickening it if desired), pour it over the celery, and serve.

Celery is well adapted (as might have been expected) to be cooked with cheese, after the manner of the corresponding dishes suggested for asparagus and salsify.

A pleasant dish also may be made by cooking some celery as directed for Celery au Jus, then mixing half of it, together with the tomato, herbs, etc., with a quarter of its bulk of cream, and passing this through a wire sieve; the remainder of the celery being dipped into well-beaten eggs and then into bread crumbs, and fried in oil or other fat. These fritters having been drained, are to be placed round a dish, and the purée poured in the centre. In her recipe for Fried Celery, Mrs Glasse suggests dipping the pieces before frying them into a batter composed of "half a pint of white wine, the yolks of three eggs beat fine, and a little salt and nutmeg; mix all well together with flour into a batter." This certainly yields a pleasant flavour. Mrs Glasse's recipe for

\section{Celery with Cream}

also gives a satisfactory result. "W Wash and clean six or eight heads of celery, cut them about three inches long, boil them tender, pour away all the water, and take the 
yolks of four eggs beat fine, half a pint of cream, a little salt and nutmeg, pour it over, keeping the pan shaking all the while. When it begins to be thick, dish it up." As a flavouring for soups and other dishes celery is thoroughly appreciated, but the old warning of "La Cuisinière Bourgeoise" must be borne in mind :- "il en fait très-peu, parce que le goût en est fort et domine sur tous les autres légumes." In "Les Dous de Cornus," the following recipe is given for a Ragoût de cellery :"Vous l'épluchez et ne mettez que les cœurs longs comme le doight. Etant blanchi, vous les faites cuire dans de bon bouillon. Après l'avoir fait égoutter, vous le mettez dans une casserole avec du blond de veau, et le faites mijotter afin qu'il prenne goût. Ensuite vous le servez avec ce que vous jugez à propos."

An excellent

\section{Celery Soup}

may be made as follows:-In an enamelled stew-pan place an ounce or two of butter. Heat in this for a few minutes four heads of celery, cleaned and selected as previously directed and cut into small slices, and a sliced onion or tomato. Before the celery has begun to brown add a pint-and-a-half of water or stock and a little pepper, salt and nutmeg. Boil for an hour and a half. Pass through a wire sieve and pour over it a quart or three pints of milk and a little cream (up to half a pint). Mix and serve.

Celeriac roots cut into slices may replace celery stems in any of the recipes given above.

It will be noticed that of the six vegetables here dealt with all are more or less interchangeable from a cookery point of view. It is for each individual to determine for. himself the particular combinations in which each vegetable more especially shines according to his own likings and 
dislikings. "Chacun à son goût" holds good in gastronomic matters, and it is to be regretted that, in this machinemade age of uniformity, all individuality in the noble art of eating has seemingly been swamped in the deluge of convention and "cumeelfo." Of one thing we may be sure, which is that the cooking of vegetables can never rise to the artistic pitch which it merits until we adopt the plan of serving them as a separate course, and so considering them on their own merits. As it is, we mostly regard them but as adjuncts to meat or game, and thus it is that all the skill of the cook and the criticism of the gourmand are reserved for the dish of meat or game, with the most dire results from the point of view of those who realise the infinite virtues which are contained in the properly prepared herbs of the garden of man.

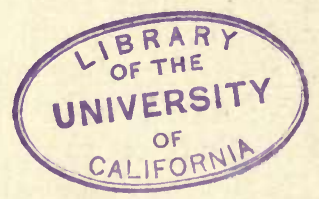




\section{Handbooks of Practical \\ Gardening}

Under the General Editorship of HARRY ROBERTS

Crown 8vo. Illustrated. Cloth, 2s. 6d. net.

The following Volumes will be published during the Spring:-

VoL. I.-THE BOOK OF ASPARAGUS. With sections also on Celery, Salsify, Scorzonera, and Seakale; together with a chapter on their cooking and preparation for the table. By Charles ILOTT, F.R.H.S., Lecturer on Horticulture to the Cornwall County Council.

VoL. II.-THE BOOK OF THE GREENHOUSE. With a special chapter on the little Town Greenhouse. By J. C. TALlaCK, F.R.H.S., Head Gardener at Shipley Hall.

VoL. III.-THE BOOK OF THE GRAPE. By H. W. WARD, F.R.H.S., for 25 years Head Gardener at Longford Castle; Author of " $\mathrm{My}$ Gardener."

VOL. IV.-THE BOOK OF OLD-FASHIONED FLOWERS. By Harry Roberts, Author of "The Chronicle of a Cornish Garden."

Other Volumes in preparation.

JOHN LANE : LONDON: VIGO STREET, w. 


\section{BOOKS FOR COUNTRY HOUSES}

The Natural History of Selborne. By GiLBERT White. Edited, with Introduction, by GRANT ALLEN. With upwards of 200 Illustrations by EDMUND H. NEW. Fcap. 4to. Price 2 Is. net.

"The most delightful form that can be imagined. The attraction lies chiefly in finding the masterpiece so admirably illustrated by Mr Edmund H. New. In black and white line work of this class he has no equal." (Country Life.)

"We have never seen this book in a more agreeable or appropriate form." (St James's Gazette)

"Mr Edmund New's drawings are nor merely artistic, but full of the poetry of association." (Speaker.)

The Compleat Angler. By Izaak Walton and Charles CotTon. Edited, with an Introduction, by Richard LE Gallienne. With Photogravure Portraits of Walton and Cotton, and over 250 Illustrations and Cover designed by EDMUND H. NEW. Fcap. 4to. Price 15s. net.

"A delightful edition, charmingly illusirated." (Punch.)

"Of Mr Edmund H. New's illustrations we cannot speak too highly.

We have never seen better." (Spectator.)

"One of the best editions; one, we cannot help thinking, that Walton himself would have preferred." (Daily Chronicle.)

\section{All About Dogs. A Book for Doggy People.} By Charles Henry Lane. With 85 Full-page Illustrations (including nearly 70 champions) by R. H. MOORE. Gilt top. Demy 8vo. Price 7s. 6d. net.

"One of the most interesting contributions to the literature of the day." (Daily Chronicle.)

"Mr Lane's book is worthy of a place on the shelves of any sporting library." (Outlook.)

"A most interesting, indeed, an entirely fascinating book." (St James's Gazette.) 


\section{BOOKS ABOUT GARDENS}

Seven Gardens and a Palace. By "E. V. B.," Author of "Days and Hours in a Garden." Illustrated by F. L. B. GriGGS and Arthur Gordon. Crown 8vo. Price 5 s. net.

Third Edition.

The Chronicle of a Cornish Garden. By Harry Roberts. With Seven ideal Illustrations by F. L. B. GrigGs. Crown 8vo. Price 5s. net.

Of Gardens : An Essay. By Francis Bacon. With an Introduction by HELEN Milman and a Cover Design and Frontispiece by Edmund N. New. Demy i6mo. Price 2s. $6 \mathrm{~d}$ net.

A Garden in the Suburbs. By Mrs Leslie Williams. With Eight Illustrations. Crown 8 vo. Price 5s. net.

Stray Leaves from a Border Garden. By Mrs Milne-Home. With Eight Illustrations by F. L. B. Griggs. Crown 8vo. Price 6 s. net.

My Vicarage Garden. By Canon ElzaсомBE, Author of "In a Gloucestershire Garden," \&c. With Illustrations by F. L. B. Griggs. Crown 8vo. Price 5s. net. In preparation.

JOHN LANE : LONDON: VIGO STREET, w. 


\section{BOOKS ABOUT' GARDENS}

In the Garden of Peace. By Helen Milman (Mrs Caldwell Crofton). With 24 Illustrations and Cover designed by Edmund H. New. Crown 8vo. Price 5s. net. Third Edition.

"Sincerity is the note of the whole book." (Globe.)

Outside the Garden. By Helen Milman (Mrs Caldwell Crofton). With 24 Illustrations and Cover by Edmund H. New. Crown 8vo. Price 5s. net.

"'Outside the Garden' fully maintains Mrs Crofton's reputation as one of Nature's keenest observers." (Daily Chronicle.)

\section{My Roses and How I Grew Them. By} Helen Milman (Mrs Caldwell Crofton). With a Cover designed by EDMUnd H. New. Crown 8 vo. Price Is. 6d. net. Third Edition.

"Pleasantly written. . . . The book is such that a novice might implicitly follow, while the more experienced may find useful hints."

(Garden.)

Flowers and Gardens. By Forbes Watson. With Photogravure Portrait of the Author. Edited, with a Biographical Note by Canon ElLacombE. Crown 8vo. Price 5s: net.

Garden-Craft Old and New. Ву Јонм D. SEDDING. With a Memorial Notice by the Rev. E. F. RUSSELL, and nine full-page Illustrations. New Edition. Demy 8vo, gilt top. Price 7s. 6d. net.

The Birds of My Parish. By E. H. Pollard. With Collotype Illustrations. Crown 8vo. Price 5s. net.

"Evelyn Pollard has a very delightful style of writing, and the story of the Birds of her Parish is charming." (Shooting Times.)

ORDER FROM YOUR BOOKSELLER 



\section{DAY USE \\ RETURN TO DESK FROM WHICH BORROWED \\ LOAN DEPT.}

This book is due on the last date stamped below, or on the date to which renewed.

Renewed books are subject to immediate recall.

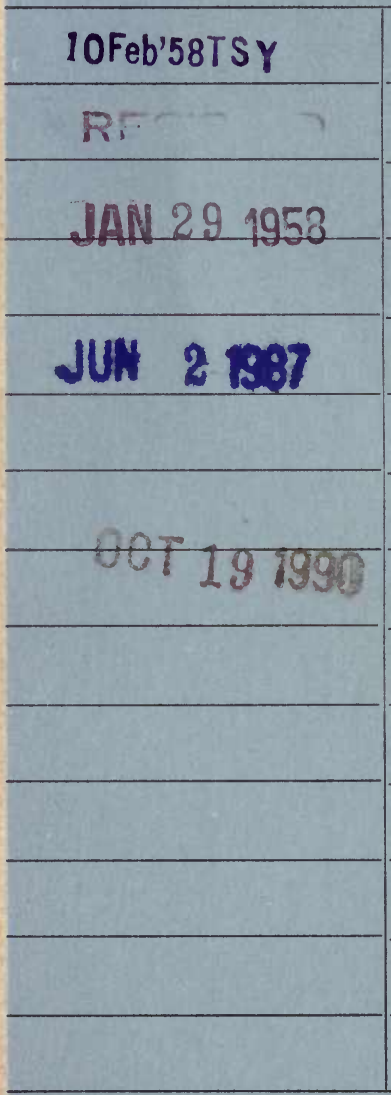




$$
\begin{aligned}
& \text { GENERAL LIBRARY - U.C. BERKELEY } \\
& \text { INOMUM }
\end{aligned}
$$

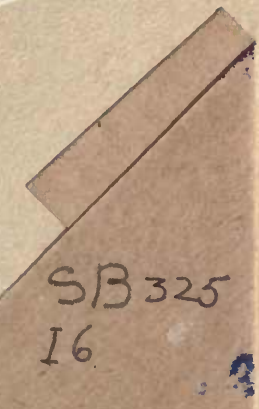

101972 
